${ }^{1}$ Unidade de Neuroendocrinologia, Divisão de Endocrinologia e Metabologia, Departamento de Clínica Médica, Faculdade de Ciências Médicas, Universidade Estadual de Campinas (Unicamp), Campinas, SP, Brasil

${ }^{2}$ Serviço de Endocrinologia e Metabologia, Departamento de Clínica Médica, Universidade Federal do Paraná (SEMPR), Curitiba, PR, Brasil

${ }^{3}$ Serviço de Endocrinologia e

Metabologia, Santa Casa de Belo Horizonte, Belo Horizonte, MG, Brasil

${ }^{4}$ Departamento de Medicina Clínica, Faculdade de Medicina da Universidade Federal do Ceará, Fortaleza, CE, Brasil ${ }^{5}$ Unidade de Neuroendocrinologia, Divisão de Endocrinologia e Metabolismo, Escola Paulista de Medicina, Universidade Federal de São Paulo (EPM-Unifesp), São Paulo, SP, Brasil ${ }^{6}$ Unidade de Neuroendocrinologia, Divisão de Neurocirurgia Funcional, Hospital das Clínicas, Faculdade de Medicina da Universidade de São Paulo, São Paulo, DP, Brasil ${ }^{7}$ Serviço de Endocrinologia, Hospita das Clínicas da Universidade Federa de Pernambuco, Recife, PE, Brasil ${ }^{8}$ Unidade de Neuroendocrinologia, Instituto Estadual do Cérebro Paulo Niemeyer, Centro de Pesquisa de Neuroendocrinologia, Hospital Universitário Clementino Fraga Filho, Universidade Federal do Rio de Janeiro, Rio de Janeiro, RJ, Brasil ${ }^{9}$ Serviço de Endocrinologia, Faculdade de Medicina da Universidade de Brasília, Brasília, DF, Brasil

${ }^{10}$ Serviço de Endocrinologia, Hospital de Clínicas de Porto Alegre; Faculdade de Medicina, Universidade Federal do Rio Grande do Sul, Porto Alegre, RS, Brasil

$"$ Serviço de Endocrinologia

Oncológica, A.C. Camargo Cancer Center, São Paulo, SP, Brasil

12 Unidade de Neuroendocrinologia, Laboratório de Endocrinologia Celular e Molecular LIM-25, Divisão de Endocrinologia e Metabolismo, Hospital das Clínicas, Faculdade de Medicina da Universidade de São Paulo, São Paulo, SP, Brasil

Correspondence to:

Heraldo Mendes Garmes

Faculdade de Ciências Médicas, Departamento de Clínica Médica, Disciplina de Endocrinologia,

Universidade Estadual de Campinas Rua Tessália Vieira de Camargo, 126 13083-887 - Campinas, SP, Brasil heraldmg@uol.com.br

Cesar Luiz Boguszewski Serviço de Endocrinologia e Metabologia, Hospital de Clínicas,

Universidade Federal do Paraná Rua Agostinho Leão Junior 285, 80030-110 - Curitiba, PR, Brasil clbogus@uol.com.br

Received on Aug/31/2020 Accepted on Nov/18/2020

\section{Management of hypopituitarism: a perspective from the Brazilian Society of Endocrinology and Metabolism}

Heraldo Mendes Garmes ${ }^{1}$

https://orcid.org/0000-0001-6117-8548

César Luiz Boguszewski²

https://orcid.org/0000-0001-7285-7941

Paulo Augusto Carvalho Miranda ${ }^{3}$

https://orcid.org/0000-0001-5433-3386

Manoel Ricardo Alves Martins ${ }^{4}$

https://orcid.org/0000-0001-7272-9552

Silvia Regina Correa da Silva ${ }^{5}$

https://orcid. org/0000-0003-2405-0013

Julio Zaki Abucham Filho 5

https://orcid. org/0000-0003-4804-1525

Nina Rosa de Castro Musolino ${ }^{6}$

https://orcid.org/0000-0003-1562-4476

Lucio Vilar ${ }^{7}$

https://orcid.org/0000-0003-4815-6963

Luiz Henrique Corrêa Portari ${ }^{5}$

https://orcid.org/0000-0002-3824-0750

Mônica Roberto Gadelha ${ }^{8}$

https://orcid.org/0000-0002-9250-3558

Leandro Kasuki ${ }^{8}$

https://orcid. org/0000-0003-1339-3192

Luciana Ansaneli Naves 9

https://orcid.org/0000-0002-3363-3803

Mauro Antônio Czepielewski ${ }^{10}$

https://orcid. org/0000-0001-5083-5776

Tobias Skrebsky de Almeida ${ }^{10}$

https://orcid.org/0000-0002-1789-0068

Felipe Henning Gaia Duarte"1

https://orcid.org/0000-0002-3495-1301

Andrea Glezer ${ }^{12}$

https://orcid.org/0000-0002-8201-6756

Marcello Delano Bronstein ${ }^{12}$

https://orcid.org/0000-0002-0113-5201

\section{ABSTRACT}

Hypopituitarism is a disorder characterized by insufficient secretion of one or more pituitary hormones. New etiologies of hypopituitarism have been recently described, including head trauma, cerebral hemorrhage, and drug-induced hypophysitis. The investigation of patients with these new disorders, in addition to advances in diagnosis and treatment of hypopituitarism, has increased the prevalence of this condition. Pituitary hormone deficiencies can induce significant clinical changes with consequent increased morbidity and mortality rates, while hormone replacement based on current guidelines protects these patients. In this review, we will first discuss the different etiologies of hypopituitarism and then address one by one the clinical aspects, diagnostic evaluation, and therapeutic options for deficiencies of TSH, ACTH, gonadotropin, and GH. Finally, we will detail the hormonal interactions that occur during replacement of pituitary hormones. Arch Endocrinol Metab. 2021;65(2):212-30

\section{Keywords}

Hypopituitarism; central hypothyroidism; secondary adrenal insufficiency; central hypogonadism and GH deficiency 


\section{INTRODUCTION}

Yypopituitarism is a heterogeneous disease characterized by insufficient secretion of one or more pituitary hormones due to genetic or acquired causes (1). The only available epidemiological data estimating the frequency of hypopituitarism in the adult population derived from a Spanish study published in 2001 showing a prevalence of 455 cases per million inhabitants and an incidence of 42.1 cases per million inhabitants per year $(2,3)$. If we consider these numbers to be true for our population, Brazil has approximately 100,000 patients with hypopituitarism and roughly 8,500 new cases per year. However, these numbers certainly underestimate the frequency of hypopituitarism, which has increased over the last years due to recognition of new etiologies, such as cerebral hemorrhage and head trauma, emergence of new etiologies, such as druginduced hypophysitis, and improvements in diagnostic tools (1). Hypopituitarism has been associated with increased mortality, particularly due to cardiovascular and cerebrovascular diseases (4). Two recent metaanalyses involving observational studies have confirmed such increased mortality, with higher rates observed especially in women and in patients of younger age at diagnosis $(5,6)$. Nevertheless, new concepts in the pathophysiology of hormonal deficiencies, recent advances in diagnostic tools, and the emergence of new formulations for hormone replacement have significantly contributed to a reduction in morbidity and mortality rates in these patients (7-10). This narrative review provides a guide for the management of patients with hypopituitarism in Brazil, considering as much as possible regional differences and health care disparities.

\section{ETIOLOGY}

Hypopituitarism is a consequence of disorders that compromise the secretory function of the anterior pituitary or interfere with the hypothalamic secretion of anterior pituitary-releasing hormones. Hypopituitarism may be secondary to genetic defects, congenital abnormalities, or acquired lesions, such as tumors, vascular abnormalities, trauma, or inflammatory, infiltrative, and infectious diseases. In the pediatric population, the most frequent causes of hypopituitarism are genetic or congenital disorders affecting the hypothalamic-pituitary region, usually associated with mutations or low expression of transcription factors responsible for pituitary development, alteration in hypothalamic hormone receptors, structural defects, or mutations in pituitary hormones or their subunits (11). On the other hand, acquired causes are more prevalent in adulthood. Despite that, pituitary tumors and their treatment with surgery and/or radiotherapy account for up to two-thirds of the cases in most literature series. Indeed, in a recent single-center Brazilian study involving 99 adult patients with hypopituitarism, around half of the patients had nontumoral causes of hypopituitarism, while $\mathrm{FSH} / \mathrm{LH}, \mathrm{GH}, \mathrm{TSH}$, and ACTH deficiencies were present in $99 \%, 98.6 \%, 96 \%$, and $81.8 \%$ of them, respectively (12). Of note, Sheehan's syndrome necrosis of the pituitary gland occurring during or soon after labor - continues to be a common cause of hypopituitarism in women in developing regions of the world (13). Aneurysmal subarachnoid hemorrhage is another nontumoral etiology associated with pituitary deficiency (14). A study carried out in Belo Horizonte, Brazil, observed some degree of pituitary dysfunction in $59 \%$ of 66 consecutive patients evaluated in the first 15 days after aneurysmal subarachnoid hemorrhage (15). However, the prevalence of hypopituitarism in this group of patients decreases in the long term, suggesting that some deficiencies are temporary and may improve over time (16).

The prevalence of hypopituitarism following traumatic brain injury (TBI) is extremely variable across studies, with percentages ranging from $16 \%$ to $69 \%$ (owing mainly to differences in study populations, severity of trauma, time of evaluation, and laboratory criteria used to define pituitary deficiency), while some authors consider these rates to be overestimated $(14,17,18)$. Brazilian investigators have studied the association between low LH and testosterone levels with morbidity and mortality during the acute phase of severe TBI, but the role of these hormones as prognostic factors is still uncertain (19). Similarly, sports-related TBI, comprising continuous or acute trauma in professional athletes, amateur sporting, or even during recreational activities, may also result in pituitary dysfunction that is commonly neglected and undiagnosed (20).

Hypophysitis, another frequently underdiagnosed cause of hypopituitarism, is related to an inflammatory process of the pituitary and may be classified as primary or secondary, depending on its etiology. Primary hypophysitis has a prevalence in the population of approximately $0.2-0.88 \%$ and an annual incidence of $1 / 9,000,000$ (21). The most common form of hypophysitis is lymphocytic or autoimmune, 
corresponding to approximately $72 \%$ of the cases $(22,23)$. Secondary hypophysitis is related to inflammatory (sarcoidosis, granulomatosis with polyangiitis), infectious (tuberculosis, syphilis, fungal infections), or infiltrative (hemochromatosis, amyloidosis, Langerhans-cell histiocytosis) diseases, or may be drug-related, as observed with two classes of immune checkpoint inhibitors, namely, cytotoxic $\mathrm{T}$ lymphocyte associated antigen (CTLA-4) and programmed cell death protein 1 receptor (PD-1) inhibitors $(21,24,25)$. Hypophysitis affects $11-12 \%$ of the patients treated with CTLA-4 inhibitors

Table 1. Main etiologies of congenital hypopituitarism (adapted from Reference 28)

\begin{tabular}{|c|c|}
\hline \multicolumn{2}{|c|}{ Etiologies of Congenital Hypopituitarism } \\
\hline Mutation & Hormonal deficiency \\
\hline \multicolumn{2}{|l|}{ Associated with syndromes } \\
\hline Kallmann Syndrome & FSH, LH \\
\hline Prader-Willi Syndrome & FSH, LH \\
\hline Laurence-Moon-Biedl Syndrome & FSH, LH \\
\hline \multicolumn{2}{|l|}{ Receptor } \\
\hline GHRH Receptor & $\mathrm{GH}$ \\
\hline CRH Receptor & ACTH \\
\hline GnRH Receptor & FSH, LH \\
\hline GPR54 & FSH, LH \\
\hline TRH Receptor & TSH \\
\hline Leptin Receptor & FSH, LH \\
\hline \multicolumn{2}{|l|}{ Structural } \\
\hline Pituitary Aplasia & Any hormonal deficiency \\
\hline Pituitary Hypoplasia & Any hormonal deficiency \\
\hline CNS Tumor, Encephalocele & Any hormonal deficiency \\
\hline \multicolumn{2}{|l|}{ Transcription factor defects } \\
\hline HESX1 & GH, PRL, TSH, LH, FSH, ACTH \\
\hline SOX2/3 & GH, PRL, TSH, LH, FSH, ACTH \\
\hline LHX3/4 & GH, PRL, TSH, LH, FSH \\
\hline PITX2 & $\mathrm{GH}$ \\
\hline PROP1 & GH, PRL, TSH, LH, FSH, ACTH \\
\hline POU1F1 & PRL, GH, TSH \\
\hline IGSF1 & PRL, GH, TSH \\
\hline TBX19 & ACTH \\
\hline NR5A1 & LH, FSH \\
\hline NR0B1 & LH, FSH \\
\hline \multicolumn{2}{|l|}{ Hormone mutation } \\
\hline GH & $\mathrm{GH}$ \\
\hline GH biologically inactive & GH \\
\hline $\mathrm{FSH} \beta$ & FSH \\
\hline LH $\beta$ & $\mathrm{LH}$ \\
\hline POMC & ACTH \\
\hline TSH $\beta$ & TSH \\
\hline Leptin & FSH, LH \\
\hline $\mathrm{PCl}$ & ACTH,FSH,LH \\
\hline Kisspeptin & FSH,LH \\
\hline
\end{tabular}

(ipilimumab and tremelimumab) and is more prevalent in men. In contrast, hypophysitis is less common during therapy with PD-1 inhibitors (nivolumab and pembrolizumab) and is rarely observed with PD-LItargeted drugs (atezolizumab, avelumab) (26). PD-1/ $\mathrm{PD}-\mathrm{Ll}$ interaction may regulate apoptosis, while PD-1/ $\mathrm{PD}-\mathrm{Ll}$ blockade may result in positive activation of the immune system with consequent inhibition of tumor growth $(21,27)$. Early recognition and appropriate management of immune-mediated hypophysitis are important to initiate pituitary hormone replacement without interrupting cancer treatment (Tables 1 and 2) (28).

Table 2. Main etiologies of acquired hypopituitarism (adapted from Reference 28)

\begin{tabular}{|c|c|}
\hline \multicolumn{2}{|c|}{ Etiologies of Acquired Hypopituitarism } \\
\hline Traumatic & Tumors \\
\hline Prior surgery & Pituitary adenoma \\
\hline Radiotherapy & Empty sella \\
\hline Traumatic brain injury & Parasellar tumors or cysts \\
\hline Infiltrating/Inflammatory & Rathke's cyst \\
\hline Primary hypophysitis & Dermoid cyst \\
\hline Lymphocytic & Meningioma \\
\hline Granulomatous & Germinoma \\
\hline Xanthomatous & Chordoma \\
\hline Secondary hypophysitis & Ependymoma \\
\hline Sarcoidosis & Glioma \\
\hline Granulomatosis with polyangiitis & Pinealoma \\
\hline Langerhans cell histiocytosis & Craniopharyngioma \\
\hline Infection & Hypothalamic hamartomas \\
\hline Hemochromatosis & Gangliocytoma \\
\hline Amyloidosis & Metastasis \\
\hline Pituitary abscess & Hematological malignancies \\
\hline \multirow[t]{2}{*}{ PIT-1 antibody } & Leukemias \\
\hline & Lymphomas \\
\hline Associated with infections & Functional \\
\hline Tuberculosis & Nutritional \\
\hline Syphilis & Excessive physical activity \\
\hline Pneumocystis jirovecii & Serious diseases \\
\hline Fungi (histoplasmosis, aspergillosis) & Acute diseases \\
\hline Parasites (toxoplasmosis) & Chronic renal failure \\
\hline \multirow[t]{4}{*}{ Viruses (cytomegalovirus) } & Chronic hepatic failure \\
\hline & Hormonal \\
\hline & Hyperprolactinemia \\
\hline & Primary hypothyroidism \\
\hline Vascular & Drug-induced dysfunctions \\
\hline \multirow{2}{*}{$\begin{array}{l}\text { Related to pregnancy (Sheehan's } \\
\text { syndrome) }\end{array}$} & Glucocorticoids \\
\hline & Dopamine agonists \\
\hline Aneurismal subarachnoid hemorrhage & Somatostatin analogs \\
\hline Pituitary apoplexy & Retinoids \\
\hline Diabetes & Anti-PD-1 monoclonal antibodies \\
\hline Hypotension & Anti-CTLA-4 monoclonal antibodies \\
\hline \multirow[t]{2}{*}{ Arteritis } & Opioids \\
\hline & Anticonvulsants \\
\hline
\end{tabular}




\section{CLINICAL MANIFESTATIONS OF HYPOPITUITARISM}

Clinical symptoms of hypopituitarism vary greatly depending on the cause, the age of the patient and speed of onset, affected pituitary hormones, and magnitude of hormone deficiency. The symptoms usually develop insidiously in adults, begin up to several years before diagnosis, and are generally nonspecific, including weakness, tiredness, lethargy, increased sensitivity to cold, discomfort, appetite loss, and weight loss or gain. Most patients with hypopituitarism have multiple pituitary hormone deficiencies, and it is challenging to assign specific signs and symptoms to a single hormone deficiency $(1,11,29,30)$. Hypopituitarism has a variable dynamic throughout its development and follow-up, characterized by a complete or sequential loss of pituitary function, which is usually permanent, although transient deficiencies with recovery years after the initial event may occur $(1,14,17,30)$. The sensitivity of the different pituitary hormones to pathological damage is variable. The usual sequential pattern of hormonal failure is loss of secretion of $\mathrm{GH}$ followed by gonadotropins, TSH, and ACTH; this order is mainly seen in patients with tumors and after radiation therapy, while hypopituitarism due to other etiologies may present with a different sequence of deficiency, for example, ACTH deficiency may be the first manifestation in hypophysitis $(1,22,30)$. Importantly, some patients may present with acute onset of pituitary hormone deficiency, while a dangerous presentation is the sudden emergence of ACTH deficiency (29).

Hypopituitarism may be associated with several metabolic and cardiovascular comorbidities, such as hypertension, unfavorable changes in body composition (with increased total and abdominal fat associated with decreased lean mass), and decreased exercise capacity, which may be accompanied by dyslipidemia, insulin resistance, premature atherosclerosis, and cardiac dysfunction (1,4-6). Insulin sensitivity varies greatly among patients with hypopituitarism, depending on numerous factors such as the etiology and treatment of the underlying cause, obesity, severity of pituitary deficiency, and inadequate hormone replacement (31). Metabolic syndrome, as defined by the National Cholesterol Education Program (NCEP) Adult Treatment Panel III criteria, has been observed in roughly $40 \%$ of the adult patients with hypopituitarism, and is associated with an increased risk of diabetes and vascular events (12,32-34).

Aside from the symptoms resulting from specific hormone deficiencies in hypopituitarism, the symptoms related to the underlying cause of hypopituitarism can dominate the clinical presentation. This is the case of pituitary tumors that induce visual changes, such as bitemporal hemianopsia due to compression of the optic chiasm, or diplopia due to invasion of the cavernous sinus and involvement of the cranial nerves crossing this sinus. Other symptoms associated with tumor growth and local invasion are headache and cerebrospinal fluid leakage. Also, in the case of functioning pituitary tumors, symptoms resulting from increased hormone secretion may coexist and predominate in the clinical presentation (1).

\section{CENTRAL HYPOTHYROIDISM (TSH DEFICIENCY)}

Central hypothyroidism $(\mathrm{CH})$ is defined by a decrease in thyroid hormone secretion secondary to insufficient TSH stimulation of a normal thyroid gland $(35,36)$. Mechanisms responsible for $\mathrm{CH}$ include decreased number of functioning thyrotrophs, decreased synthesis and/or secretion of hypothalamic TRH, decreased TRH release to the pituitary, and decreased biologic activity of TSH. In most cases, $\mathrm{CH}$ is associated with other pituitary deficiencies. The signs and symptoms of $\mathrm{CH}$ are similar to those present in primary hypothyroidism, including somnolence, tiredness, mild weight gain, cold intolerance, constipation, dry skin, and bradycardia. The main differences of $\mathrm{CH}$ compared with primary hypothyroidism are usually the absence of goiter and reduced severity of the symptoms $(35,36)$.

The laboratory diagnosis of $\mathrm{CH}$ is based on low serum free T4 (FT4) levels concomitant with a low or inappropriately normal TSH level $(35,36)$. Less commonly, serum TSH may be mildly elevated, usually below $10 \mathrm{IU} / \mathrm{L}$. The measurement of total T4 may replace the measurement of FT4 in the diagnosis of childhood-onset $\mathrm{CH}$, but the accuracy of total $\mathrm{T} 4$ is poorer in adulthood-onset $\mathrm{CH}$, as approximately $45 \%$ of these patients have total $\mathrm{T} 4$ within the normal reference range. Of note, FT4 levels remain within the low-normal range in approximately $18 \%$ of the patients with adulthood onset $\mathrm{CH}$ (37). The TRH test and serum T3 levels are not useful for diagnosing $\mathrm{CH}$. In longitudinal follow-up, a decrease of more than $20 \%$ in FT4 levels should alert for an increased risk of $\mathrm{CH}$, even when the values remain within the low-normal range (35-37). 
The diagnosis of subclinical CH (normal FT4) is cumbersome and difficult to confirm by serum thyroid function markers. On Doppler echocardiography, abnormal presystolic time measurements have been demonstrated in patients with subclinical $\mathrm{CH}$, but further studies are needed before recommendation of widespread use of this parameter (38). Other markers of thyroid hormone peripheral actions, such as serum cholesterol, sex-hormone-binding globulin (SHBG), carboxy-terminal telopeptide of type I collagen, osteocalcin (also known as bone gammacarboxyglutamic acid [Gla]-containing protein), and IL-2 soluble receptor (sIL-2R) have also been used to better define subclinical $\mathrm{CH}$, but thus far, they have not shown good accuracy (36).

The mainstay of hormone replacement in $\mathrm{CH}$ is levothyroxine (LT4). Replacement with T3 is currently not recommended due to lack of evidence showing clinical superiority to LT4 replacement and safety $(39,40)$. In adult patients, the average dose of LT4 is $1.6 \mu \mathrm{g} / \mathrm{kg} /$ day but varies depending on the duration of the disease, number of additional pituitary deficiencies, and concomitant replacement with GH and/or estrogens (37,39-41). In most cases, LT4 treatment can be started at full dose, except in older individuals or in patients with cardiac or neurological diseases, in whom therapy should be initiated at lower doses and titrated up with caution. In these cases, symptoms and serum FT4 levels should be assessed at 6- to 8-week intervals during titration and every 6-12 months thereafter. Of note, evaluation of the adrenal axis is recommended, and if concomitant ACTH deficiency is present, LT4 replacement should only be initiated after glucocorticoid replacement due to the risk of adrenal crisis $(30,35,36)$. Dose adjustments of LT4 may be necessary during concomitant treatment with $\mathrm{GH}$ in children, since $\mathrm{GH}$ replacement increases $\mathrm{T} 4$ to $\mathrm{T} 3$ conversion (41).

Levels of FT4 in the lowest tertile of the reference range have been associated with unfavorable metabolic profile in patients with $\mathrm{CH}$. Thus, targeted serum FT4 levels during LT4 replacement should be into the upper half of the reference range, with blood samples collected before the daily LT4 intake $(39,40,42)$. On the other hand, higher LT4 doses should also be avoided due to the increased risk of thyrotoxicosis symptoms, adrenal crisis, and osteoporosis (43). Measurement of TSH and T3 levels are usually unnecessary and not recommended during LT4 therapy in $\mathrm{CH}$ (30). However, low/ undetectable TSH is expected in patients with $\mathrm{CH}$ on adequate thyroid hormone replacement, whereas a high T3 level indicates excessive thyroid hormone replacement requiring dose adjustments. LT4 requirements increase by $20 \%$ to $50 \%$ during pregnancy in patients with primary hypothyroidism, but patients with $\mathrm{CH}$ generally do not require a similar increase due to preservation of the thyroid response to the thyroidstimulating effect of $\beta$-hCG (44).

\section{SECONDARY ADRENAL INSUFFICIENCY (ACTH DEFICIENCY)}

Secondary adrenal insufficiency (SAI) may occur due to deficiency of ACTH or CRH in disorders of the pituitary or hypothalamus, resulting in decreased secretion of adrenal cortex steroids, mainly cortisol and dehydroepiandrosterone (DHEA) $(45,46)$. SAI is one of the least frequent pituitary function alterations in most patients with hypopituitarism due to pituitary tumors, but it may be the initial presentation in other etiologies, such as in drug-induced hypophysitis $(22,47)$. The prevalence of SAI after surgery for treatment of pituitary adenomas varies widely, while this condition may also develop years after radiotherapy (30). SAI increases the risk of morbidity and mortality in patients with hypopituitarism, since it predisposes patients to adrenal crisis in situations of acute stress and intercurrent illness (48).

SAI manifests with nonspecific symptoms, such as nausea, dizziness, fatigue, anorexia, weight loss, and hypotension, thus requiring a high index of suspicion. Mild ACTH deficiency may only be clinically significant under concurrent stress or illness. The presence of normochromic normocytic anemia, eosinophilia, hyponatremia, hypoglycemia, and eventually hyperkalemia, should serve as a warning sign of increased risk of SAI in a patient with hypopituitarism $(30,45,46)$. Nevertheless, long delays in diagnosing SAI are common, and in many patients, this condition is only established after hospitalization due to adrenal crisis, a potentially life-threatening medical condition requiring immediate emergency treatment. Adrenal crisis should be suspected in patients presenting with acute shock refractory to adequate fluid resuscitation and vasopressors (49). Estimates of yearly rates in patients with adrenal insufficiency in Europe project an incidence of adrenal crises of 5-10 per 100 patients and a mortality rate of 0.5 per 100 patient-years, 
corresponding to a number of deaths between 5,000 10,000 (49). Although a correct and prompt diagnosis of acute SAI is crucial for indicating appropriate therapy and preventing complications, the diagnostic investigation can be challenging in many cases, such as in critically ill patients (50). Importantly, diagnostic tests should never delay the prompt start of life-saving hydrocortisone treatment in suspected adrenal crisis (46). In the clinical context of hypopituitarism, the demonstration of morning cortisol levels collected at 8-9 AM lower than $100 \mathrm{nmol} / \mathrm{L}(3 \mu \mathrm{g} / \mathrm{dL}$ ) are strongly predictive of SAI, whereas values greater than $15 \mu \mathrm{g} / \mathrm{dL}$ exclude this diagnosis. Of note, severely ill patients with SAI may present with morning cortisol levels greater than $500 \mathrm{nmol} / \mathrm{L}(18 \mu \mathrm{g} / \mathrm{dL})$. Patients with morning cortisol values between $3-15 \mu \mathrm{g} / \mathrm{dL}$ require additional hormonal evaluation (30); in recommending such assessment, it is important to consider that normal individuals have morning cortisol values ranging from 6-15 $\mathrm{\mu g} / \mathrm{dL}$ by most immunoassays $(30,45,46)$. Despite considered the gold standard for diagnosis of SAI, the insulin tolerance test (ITT) requires adequate site and trained staff and is contraindicated in patients with epilepsy, cardiac arrhythmias, and cerebrovascular diseases. SAI is diagnosed if peak cortisol during ITT is lower than $500 \mathrm{nmol} / \mathrm{L}(18 \mu \mathrm{g} / \mathrm{dL})$, although new immunoassay methods standardized against mass spectrometry can show lower concentrations, around $350 \mathrm{mmol} / \mathrm{L}(12 \mu \mathrm{g} / \mathrm{dL})$. An alternative to ITT is the glucagon stimulation test (GST), which should be interpreted similarly to the ITT, but exhibits lower sensitivity and specificity (51). The simplest strategy to assess SAI is the short Synacthen test (or Cosyntropin test), in which serum cortisol levels are measured before and 30 and 60 minutes after stimulation with $250 \mu \mathrm{g}$ of synthetic ACTH (52); a cortisol peak value below 500 nmol/L (< $18 \mu \mathrm{g} / \mathrm{dL})$ confirms SAI. Unfortunately, Synacthen and Cosyntropin are not easily available in Brazil, hindering the use of these tests in clinical practice. The test may present false-negative results in SAI, especially within 4 weeks from a pituitary insult or surgery or in partial forms of the disease (46). A lowdose test ( $1 \mu \mathrm{g}$ of synthetic ACTH) has been proposed, but has not shown any clear advantages compared with the traditional test (53) (Figure 1).

In patients receiving glucocorticoid replacement, the exogenous glucocorticoid may suppress the hypothalamic-pituitary-adrenal axis and interfere with cortisol measurement. Patients using hydrocortisone

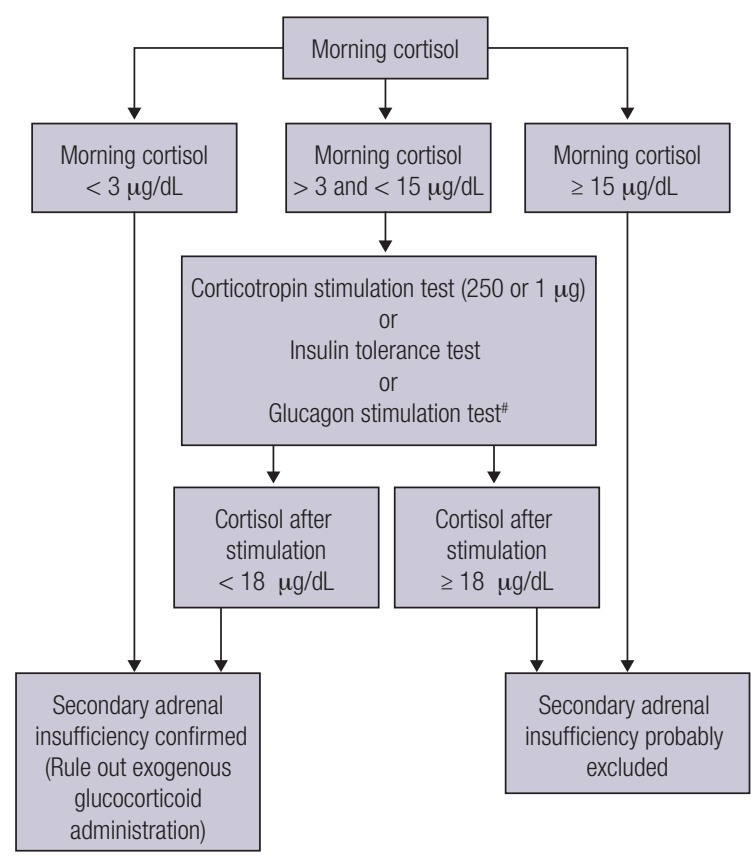

Figure 1. Hormonal investigation of secondary adrenal insufficiency (SAI)* *The cut-off values of serum cortisol levels may change according to the method used for evaluation. \# Cut-off value $<9,0 \mu \mathrm{g} / \mathrm{dL}$.

can undergo serum cortisol assessment 24 hours after the last dose, but in those using prednisone or prednisolone, this period may be longer, requiring individual assessment based on the dose and the time of the last dose. These drugs may cross-react with cortisol measurement assays at different extents, and the duration of their suppression on the hypothalamicpituitary-adrenal axis lacks consensus in the literature $(54,55)$. Moreover, interference of oral estrogen should also be considered in the interpretation of the test results, since oral estrogen can increase serum cortisol levels by $20-50 \%$ due to increase in $\mathrm{CBG}$ concentrations, but does not affect salivary or urinary free cortisol measurements (56). There is no consensus in the literature about the diagnosis of complete or partial forms of SAI, which makes the diagnostic scenario even more complex. In this context, clinical judgment in each case is fundamental, and the general rule is to avoid excessive treatment. Plasma ACTH levels have no value in the diagnosis of SAI, and undetectable ACTH alone is unable to establish this diagnosis; this contrasts with a finding of elevated ACTH levels associated with low cortisol levels, which defines the diagnosis of primary adrenal insufficiency (Addison's disease) (57). Other hormone alterations in patients with SAI include decreased or undetectable levels of DHEA and S-DHEA, particularly in younger patients. 
Women with panhypopituitarism and SAI have severe androgen deficiency, although the clinical importance of this finding is still unclear $(46,57)$.

Once the diagnosis of SAI is confirmed, glucocorticoid replacement with one of the commercially available synthetic derivatives is recommended. Mineralocorticoid therapy is not necessary in SAI $(30,46)$. Ideally, hydrocortisone should be the drug of choice for long-term SAI management, but the type of therapy and dosing regimen varies widely worldwide. In an international survey, $80 \%$ of the patients reported use of hydrocortisone, followed by prednisone/prednisolone $(10 \%)$, cortisone acetate $(3 \%)$, dexamethasone $(3 \%)$, and other therapies $(3 \%)$ (58). The daily dosage of hydrocortisone ranges between $15-20 \mathrm{mg}$ divided into two to three doses; the largest dose should be taken upon awakening, followed by another dose close to lunchtime and, if needed, a third dose in the afternoon no later than 4-6 PM. Hydrocortisone and cortisone acetate are not widely available in Brazil, and the prescription of these salts by compounding pharmacies raises concerns about the origin, preservation, storage, packaging, and bioequivalence of these products and, therefore, are not recommended (30). Consequently, other formulations such as prednisone and prednisolone are more frequently prescribed. Prednisone is usually administered once daily in the morning, in doses ranging from $2.5-5.0 \mathrm{mg}$ per day. Dose equivalence of hydrocortisone and prednisone can be calculated by the formula $1 \mathrm{mg}$ prednisone $=4 \mathrm{mg}$ hydrocortisone (59). Regardless of glucocorticoid type, replacement therapy in SAI should start with lower-range dosage regimens with up-titration according to the patient's clinical status while avoiding overreplacement. During stress or intercurrent illness, patients should be instructed to double or triple the dose until resolution of the underlying condition. Patients, family members, and other health professionals should be educated about the correct adjustment of glucocorticoid dosage and informed on how to identify the precipitating factors and symptoms of adrenal crisis. In addition, patients should carry an identification and emergency card and be encouraged to use medical alert bracelets $(45,46,49)$. In Brazil, educational material and emergency kits for patients with adrenal insufficiency are provided by the Associação Brasileira Addisoniana through their website at www.abaddison.org.br.

Modified-release hydrocortisone preparations have been developed to provide a more physiological replacement therapy, replicating the circadian rhythm of normal cortisol secretion (56). These compounds are formed by a dual-release formulation, consisting of one extended-release core surrounded by an immediaterelease coating. One of these drugs, marketed as Plenadren, has been approved in Europe and seems to have some metabolic advantages over the conventional hydrocortisone $(60)$. However, treatment cost is much higher with these drugs, and they have no perspective of receiving approval in Brazil.

There is no specific and accurate biomarker to guide glucocorticoid replacement, which leads clinicians to rely on subjective clinical assessments to adjust therapy. Not surprisingly, a real-world study of glucocorticoid replacement involving patients from the European Adrenal Insufficiency Registry (EU-AIR) identified 25 different regimens being used to deliver a daily hydrocortisone dose of $20 \mathrm{mg}$ in clinical practice (61). Conflicting evidence has been shown regarding the effects of multiple treatment strategies on adverse health outcomes, such as quality of life (QoL), bone density, metabolic profile, and risk of adrenal crisis or death (59). However, prolonged use of doses higher than $20 \mathrm{mg}$ of hydrocortisone or equivalent per day must be avoided as they have been associated with unfavorable metabolic profile, Cushing-like morbidities, and increased mortality in patients with hypopituitarism (62).

\section{HYPOGONADOTROPIC HYPOGONADISM (FSH/LH DEFICIENCY)}

Hypogonadotropic hypogonadism $(\mathrm{HH})$, also known as central or secondary hypogonadism, can be congenital or, more often, acquired. A detailed description of isolated congenital forms of $\mathrm{HH}$ is beyond the scope of this article (for a review on this topic, see Reference 63). Acquired HH is very common in patients with hypopituitarism due to pituitary adenomas and/or their treatment with surgery or radiotherapy, usually accompanied by other pituitary hormone deficiencies (12). Anorexia nervosa, excessive exercise, and psychological distress are common causes of acquired $\mathrm{HH}$ in women, and medications such as opiates, psychotropic agents, and glucocorticoids, can induce $\mathrm{HH}$ in both sexes. In adults, clinical features of $\mathrm{HH}$ in men include decreased libido, erectile dysfunction, and infertility, and in women include oligomenorrhea or amenorrhea, decreased libido, dyspareunia, and infertility that can be aggravated 
by concomitant hyperprolactinemia and adrenal/ ovarian androgen deficiency (30). Prolonged estrogen deficiency may cause regression of secondary sexual characteristics, urinary symptoms, reduction of muscle mass and bone density, and dyslipidemia. Similarly, prolonged testosterone deficiency has been associated with an increased risk of metabolic disorders $(64,65)$. Untreated $\mathrm{HH}$ is an independent factor related to high mortality due to vascular complications in patients with hypopituitarism, particularly women, and adequate replacement with sex steroids has been shown to normalize or reduce mortality rates in these patients $(5,6,66)$.

In women, amenorrhea in the clinical context of a hypothalamic-pituitary disease indicates the presence of $\mathrm{HH}$, which is confirmed by low estradiol levels associated with low or inappropriately normal $\mathrm{FSH} / \mathrm{LH}$ levels (30). Similarly, low total testosterone levels associated with low or inappropriately normal FSH/LH levels establish the diagnosis of $\mathrm{HH}$ in men. Measurement of total testosterone should be performed before 10 AM after overnight fasting, in the absence of acute/ subacute illness and medications (glucocorticoids, opiates, ketoconazole, barbiturates, cocaine, etc.) known to affect testosterone levels. Two measurements with the same type of assay are necessary to establish the diagnosis of low testosterone in cases of borderline values. There is no indication for stimulation tests (67).

\section{Sex steroid replacement therapy}

Treatment of male $\mathrm{HH}$ involves primarily testosterone replacement, with the goal of improving sexual function, libido, energy levels, bone mineral density (BMD), sense of well-being, muscle mass, and strength. Current guidelines recommend the use of minimal doses necessary to maintain testosterone levels in the range of $450-600 \mathrm{ng} / \mathrm{dL}(30,67)$. Different testosterone formulations are available, and an individualized therapeutic approach is needed considering effectiveness, patient compliance and preference, drug cost and availability, and potential side effects (68-70).

Long-acting testosterone undecanoate is often considered the best option among injectable preparations due to its more convenient administration (intramuscular, every 10 to 14 weeks). This regimen usually maintains plasma testosterone levels in the expected range with minor fluctuations (68-70).
Intramuscular formulations containing testosterone enanthate, cypionate, or the combination of four esters (propionate, phenylpropionate, isocaproate, and decanoate) are usually administered every 2 to 3 weeks, and are efficacious and generally well tolerated (71). Although these formulations are much less expensive than testosterone undecanoate, they are associated with supraphysiologic peak values shortly after the injection and to subphysiologic levels on the days before the new injection. This often leads to fluctuations in symptoms, mood swings, and emotional instability (71). Transdermal gel formulations are commonly prescribed, as they provide flexibility of dosing, ease of application, good skin tolerability, and possibly less erythrocytosis than injectable testosterone (68-70). The disadvantages of transdermal gel formulations include the potential of transferring of testosterone to women or children by direct skin-to-skin contact, and skin irritation in a small proportion of treated men (68-70). Testosterone undecanoate is the only safe testosterone ester for oral therapy, since it is well tolerated and not hepatotoxic, but it must be taken twice daily with fatty meals $(68,72)$. It has been approved in the US market, but it is still not available in Brazil. Additionally, a nasal gel formulation and a subcutaneous testosterone enanthate formulation for weekly administration have been recently approved by the US Food and Drug Administration (FDA) $(73,74)$ (Table 3). Testosterone therapy should not be started in men with breast or prostate cancer, palpable prostate nodule or induration, and prostate-specific antigen $(\mathrm{PSA})>4 \mathrm{ng} / \mathrm{mL}$ or $>$ $3 \mathrm{ng} / \mathrm{mL}$ in those at increased risk of prostate cancer (e.g., men with a first-degree relative with diagnosed prostate cancer) without further urological evaluation, elevated hematocrit, untreated severe obstructive sleep apnea, severe lower urinary tract symptoms, uncontrolled heart failure, myocardial infarction or stroke within the last 6 months, or thrombophilia. After starting testosterone therapy, patients should be monitored with measurement of hematocrit and PSA levels in the first year of treatment to investigate possible side effects (67).

Sex steroid replacement should be started in all women with $\mathrm{HH}$ who are at premenopausal age and be individualized for older women $(30,68)$. Noteworthy, hypopituitarism removes the natural survival advantage that women have over men in terms of vascular complications; therefore, outcomes observed in natural menopause should not be extrapolated to women with 
Table 3. Testosterone (T) formulations and commercial names (in parentheses)

\begin{tabular}{|c|c|c|c|}
\hline Formulation & Dosage & Advantages & Disadvantages \\
\hline $\begin{array}{l}\text { Injectable long-acting } \\
\text { T undecanoate in oil (Nebido, Hormus) }\end{array}$ & $\begin{array}{l}1000 \mathrm{mg} \text { IM, followed by } 1000 \mathrm{mg} \text { at } \\
6 \text { weeks; then, } 1000 \text { mg every } 10-14 \\
\text { weeks }\end{array}$ & $\begin{array}{l}\text { Convenient drug regimen (once every } \\
\text { 10-14 weeks); stable T levels }\end{array}$ & $\begin{array}{l}\text { Requires IM injection of a large volume } \\
\text { ( } 3 \text { or } 4 \mathrm{~mL} \text { ); coughing (rarely); coughing } \\
\text { episode immediately after injection } \\
\text { (rarely); high cost }\end{array}$ \\
\hline T enanthate (Delatestryl)* & $\begin{array}{l}100-200 \mathrm{mg} \text { IM every 2-4 weeks or } \\
100 \mathrm{mg} / \text { week }\end{array}$ & \multirow[t]{3}{*}{$\begin{array}{l}\text { Flexibility of } \\
\text { dosing; low cost }\end{array}$} & \multirow{3}{*}{$\begin{array}{l}\text { Requires IM injection; peaks and valleys } \\
\text { in serum T concentrations that may } \\
\text { be associated with fluctuations in } \\
\text { symptoms; coughing immediately after } \\
\text { injection (very rarely) }\end{array}$} \\
\hline T cypionate (Deposteron) & $\begin{array}{l}\text { 100-200 mg IM every 2-4 weeks or } \\
100 \text { mg/week }\end{array}$ & & \\
\hline $\begin{array}{l}\text { T proprionate }+ \text { isocaproate }+ \\
\text { decanoate }+ \text { phenylpropionate } \\
\text { (Durateston) }\end{array}$ & $\begin{array}{l}\text { 125-250 mg IM every 2-4 weeks or } \\
125 \text { mg/week }\end{array}$ & & \\
\hline $\begin{array}{l}\text { Subcutaneous T enanthate } \\
\text { (Xyosted)* }^{*}\end{array}$ & $\begin{array}{l}\text { Starting dose: } 75 \mathrm{mg} \text { subcutaneously } \\
\text { once a week. The dose can be titrated } \\
\text { to } 50 \mathrm{mg} \text { or } 100 \mathrm{mg} \text { weekly }\end{array}$ & $\begin{array}{l}\text { Convenient drug regimen (once } \\
\text { weekly); stable T levels }\end{array}$ & $\begin{array}{l}\text { Increases in hematocrit, PSA, and blood } \\
\text { pressure are the most frequent side } \\
\text { effects }\end{array}$ \\
\hline Transdermal T gel(Androgel) & $\begin{array}{l}50-100 \mathrm{mg} \text { of } 1 \% \text { transdermal gel } \\
\text { once daily }\end{array}$ & $\begin{array}{l}\text { Provides flexibility of dosing, ease of } \\
\text { application, good skin tolerability; less } \\
\text { erythrocytosis than injectable T }\end{array}$ & $\begin{array}{l}\text { Potential of transfer to a female partner } \\
\text { or child by direct skin-to-skin contact; } T \\
\text { concentrations may be variable from } \\
\text { application to application; skin irritation } \\
\text { in a small proportion of patients }\end{array}$ \\
\hline Axillary T solution (Axeron) & $\begin{array}{l}60 \mathrm{mg} \text { of T solution applied in the } \\
\text { axillae }\end{array}$ & Provides good skin tolerability & Similar to $1 \%$ testosterone gel \\
\hline Transdermal T patch (Androderm)* & $\begin{array}{l}\text { One or two patches, designed to } \\
\text { deliver } 2-4 \text { mg of T during } 24 \text { hours } \\
\text { applied on a clean, dry area of skin on } \\
\text { the arm, back, abdomen, or upper } \\
\text { buttocks (once daily for most patients) }\end{array}$ & Ease of application; stable T levels & $\begin{array}{l}\text { Serum T concentrations in some } \\
\text { T-deficient men may be in the } \\
\text { low-normal range; these men may need } \\
\text { applications of two patches daily; skin } \\
\text { irritation at the application site occurs } \\
\text { frequently }\end{array}$ \\
\hline Buccal, bioadhesive, $T$ tablets (Striant) $^{\star}$ & $\begin{array}{l}30 \mathrm{mg} \text { controlled release, bioadhesive } \\
\text { tablets BID }\end{array}$ & Convenience and discreet & $\begin{array}{l}\text { Twice daily applications are required. } \\
\text { Gum-related adverse eventsin } 16 \% \text { of } \\
\text { treated men; alterations in taste }\end{array}$ \\
\hline T pellets (Testopel)* & $\begin{array}{l}\text { T Pellets containing } 600-1200 \mathrm{mg} \mathrm{T} \\
\text { implanted SC; the number of pellets } \\
\text { and the regimen may vary with } \\
\text { formulation }\end{array}$ & $\begin{array}{l}\text { Requires infrequent } \\
\text { administration }\end{array}$ & $\begin{array}{l}\text { Surgical incision for insertions is } \\
\text { required; occasional spontaneous pellets } \\
\text { extrusion; local hematoma and infection } \\
\text { rarely seen }\end{array}$ \\
\hline Nasal T gel (Natesto) & $11 \mathrm{mg}$ two or three times daily & $\begin{array}{l}\text { Rapid absorption and avoidance of first } \\
\text { pass metabolism }\end{array}$ & $\begin{array}{l}\text { Multiple daily intranasal dosing required; } \\
\text { local nasal side-effects (rhinorrhea, } \\
\text { epistaxis, nasal discomfort, nasal } \\
\text { congestion, parosmia); not appropriate } \\
\text { for men with nasal disorders }\end{array}$ \\
\hline Oral T undecanoate (Jatenzo)* & $\begin{array}{l}\text { Starting dose: } 237 \mathrm{mg} \text { orally once in } \\
\text { the morning and once in the evening } \\
\text { (with meals). If needed, adjust the dose } \\
\text { to a minimum of } 158 \mathrm{mg} \text { BID and a } \\
\text { maximum of } 396 \mathrm{mg} \mathrm{BID}\end{array}$ & $\begin{array}{l}\text { Convenience of } \\
\text { oral administration }\end{array}$ & $\begin{array}{l}\text { Variable clinical responses; } \\
\text { administration with fatty meal is } \\
\text { required; fat content of meals affects } \\
\text { bioavailability; variable serum T } \\
\text { concentrations }\end{array}$ \\
\hline
\end{tabular}

* Not available in Brazil. IM: intramuscular; BID: twice daily; PSA: prostate-specific antigen. Adapted from Bhasin et al. Testosterone therapy in men with hypogonadism: an Endocrine Society Clinical practice guideline. J Clin Endocrinol Metab. 2018,103:1715-44.

hypopituitarism presenting with frank hypogonadism (75). In this regard, data of 203,767 postmenopausal women from 10 observational studies included in the International Collaboration for a Life Course Approach to Reproductive Health and Chronic Disease Events (InterLACE) indicated that primary hypogonadism due to surgical menopause was associated with over $20 \%$ higher risk of cardiovascular disease compared with natural menopause, with an increased risk in women younger than 40 years. Women who experienced surgical menopause at an earlier age $(<50$ years $)$ and received hormone replacement therapy had a lower risk of incident heart disease than those who were not treated (76). Assuming that untreated FSH/LH insufficiency may have a negative rather than a beneficial effect on survival, it is unfortunate that $\mathrm{HH}$ is significantly more 
frequently underdiagnosed and undertreated in women compared with men $(77,78)$.

While the goal of treatment of $\mathrm{HH}$ in older women is to control hot flushes, in young women, the goal is to prevent damage induced by estrogen deficiency. Adult women with $\mathrm{HH}$ should receive combined estrogenprogestogen regimen or unopposed estrogens (if prior hysterectomy) for improving symptoms of hypoestrogenism such as vaginal atrophy, dysuria, dry skin/hair, hot flushes, and night sweats, and to reduce the risk of cardiovascular disease, osteopenia, and mortality $(30,68)$. The choice of estrogen and progestin formulations, route (oral or transdermal), and regimen depends on the risk of adverse effects, patient's convenience/preference, and cost. Transdermal administration of estrogens either by patch or gel provides more stable plasma concentrations of estradiol and reduces its conversion to estrone compared with oral formulations. By eliminating the first pass through the liver, transdermal estrogen prevents undesirable increases in coagulation factors, blood pressure, and serum triglycerides. In addition, by interfering less with SHBG levels, transdermal estrogen allows a greater fraction of hormone to circulate in free and biologically active forms $(68,79)$. The usual doses of transdermal estrogen are 50-100 $\mu \mathrm{g}$ of estradiol daily, applied as a patch twice weekly, or $1.5 \mathrm{mg}$ daily of estradiol hemihydrate gel. The addition of progestogens to the patch does not affect the absorption of estrogen. Some application systems use patches containing varying amounts of estradiol that mimic the physiological variations of estradiol levels throughout the menstrual cycle. Some patients may develop allergy at the patch application site or exhibit a drop in estrogen levels earlier than expected (68). Furthermore, the transdermal route of estrogen administration does not block the hepatic generation of IGF-1 induced by GH (79).

For use in oral preparations, natural estradiol such as 17-beta-estradiol should be micronized or administered in derivative compounds such as ethinyl estradiol, or estradiol valerate, enanthate, or cypionate, to improve absorption. Benefits of oral estradiol therapy include relatively low cost, long accumulated experience, convenience, increased HDL-cholesterol, and reduced LDL-cholesterol $(68,79)$. Another alternative to oral estradiol replacement are conjugated estrogens, a combination of estrogens obtained from urine of pregnant mares. The induction of protein synthesis in the liver by conjugated estrogens is even higher than that observed with the use of estradiol formulations (80). Daily doses of estrogen in adult women with $\mathrm{HH}$ range from 1.0 to $2.0 \mathrm{mg}$ of micronized estradiol or an equivalent dose of other estrogens. In general, these doses lead to clinical improvement and serum estradiol levels between $30-50 \mathrm{pg} / \mathrm{mL}$, which correspond to the levels observed in the early follicular phase $(68,80)$. A Brazilian study evaluating bone mass in patients with premature ovarian failure has shown that the doses of estrogen normally used in postmenopause were not adequate to reduce impaired spinal and femoral bone mass in younger women (81), although no consensus in the literature has established the required estrogen dose in this age group.

Cyclic progesterone replacement combined with continuous estrogen prevents endometrial hyperplasia and induces menstruation. In this regimen, 2.5 to 10 mg of medroxyprogesterone acetate (MPA) or synthetic progestogenic derivative is added during 7 to 10 days of the month. Alternatively, estrogens and progestogens can be used simultaneously and continuously, which induces a higher frequency of amenorrhea (80). Alternatives to MPA are micronized progesterone (100$200 \mathrm{mg}$ daily) and progestogens such as norethindrone $(0.35 \mathrm{mg})$, gestodene $(0.75 \mathrm{mg})$, or levonorgestrel $(0.075 \mathrm{mg})$, which exhibit different affinities for the progesterone, testosterone, estradiol, and aldosterone receptors, and consequently have variable side effects (80). Endometrial proliferation should be controlled periodically by transvaginal ultrasonography. If endometrial thickening greater than $5 \mathrm{~mm}$ is observed, an endometrial biopsy should be performed (82).

Combined estrogen-progestin contraceptive pill may be more acceptable for younger women, but studies comparing the effects of different dose regimens in $\mathrm{HH}$ are lacking (30). After the age of physiological menopause, the prescription of estrogens should be based on current postmenopausal guidelines. Nevertheless, a recent systematic review comprising $2,588,327$ postmenopausal women from six clinical trials and 27 prospective observational studies has observed that doses of $0.3-0.625 \mathrm{mg} /$ day of oral conjugated equine estrogen or equivalent have been associated with cardioprotective effects, while higher doses increase the risk of venous thromboembolism and stroke in a dose-dependent manner. The authors concluded that hormone therapy should be used in the lowest effective dose to prevent adverse cardiovascular effects and that the dose should be reduced with advancing age (83). 
They also observed that transdermal estrogen may be safer in relation to cardiovascular and thrombotic risk than oral estrogen and that preparations with MPA are associated with increased thrombotic risk (83).

Women with $\mathrm{HH}$ have androgen deficiency. Although few studies have shown advantages with treatment (84), recent guidelines recommended against the routine use of DHEA and testosterone in women due to limited data concerning efficacy and safety $(30,85,86)$. An intravaginal form of DHEA has been approved by the FDA to treat genitourinary syndrome of menopause, but this formulation is not available in Brazil (87). Moreover, testosterone has been carefully suggested in the guidelines to treat selected women with hypoactive sexual desire disorder (85-87). In this clinical context, which might be present in women with hypopituitarism, a trial of low-dose testosterone therapy may be considered, which seems to be safe in the short term. However, efficacy is variable and long-term effects on cardiovascular risk and breast cancer incidence are not known. Undesirable side effects, such as alopecia, changes in vocal timbre, hirsutism, clitoromegaly, acne, elevated hematocrit, and liver function and lipid profile abnormalities, must be balanced against the potential benefits (85-87).

\section{Fertility issues}

Fertility issues in patients harboring aggressive pituitary tumors have been recently revisited (88). Importantly, fertility preservation strategies need to be discussed with the patient desiring conception before or during treatment. Additional pituitary deficiencies should be appropriately treated, particularly GH deficiency, which has been associated in some studies with poor pregnancy rates in patients with hypopituitarism (89). In men and women with $\mathrm{HH}$, the approach to restoring fertility may include clomiphene citrate, human chorionic gonadotropin (hCG), human menopausal gonadotropin, or purified or recombinant FSH (88). Pulsatile GnRH administration via mini-infusion pump is only delivered in some research settings worldwide (63).

In men with fertility issues, testosterone replacement treatment should be discontinued. In men with prolactinomas and persistent hypogonadism under dopamine agonist therapy, clomiphene restores normal testosterone levels and improves sperm motility, independent of prolactin levels (90). In contrast, clomiphene treatment fails to restore normal testosterone levels in men with hypogonadism harboring nonfunctioning pituitary adenomas (91). A study reported that $67 \%$ of men with $\mathrm{HH}$ and acromegaly treated with clomiphene achieved normal testosterone levels, but fertility restoration was not evaluated (92). Administration of hCG is done intramuscularly or preferably subcutaneously in the thigh at an initial dose of 3,000-5,000 IU per week, divided into at least two injections to ensure relatively stable serum levels (63). Serum testosterone concentration is measured every 2 or 3 months, and the dose should be increased if the values are not between 400 and $800 \mathrm{ng} / \mathrm{dL}$. Very rarely, serum testosterone concentration fails to respond to hCG, even at a very high dose, due to antibodies to hCG (93). If the sperm count does not reach 5-10 million/mL and/or pregnancy has not occurred within 6 months after serum testosterone is between 400-800 $\mathrm{ng} / \mathrm{dL}$, purified or recombinant FSH should be added to the regimen with a starting dose of 75-150 IU every other day (or three times per week). This dose is adjusted upwards if necessary to achieve serum FSH concentration in the physiologic range of 4-8 IU/L (63). These regimens induce testicular growth in almost all patients, spermatogenesis in approximately $80 \%$, and pregnancy in $50 \%$ of the cases after $12-24$ months of treatment (88).

In women, clomiphene citrate may induce ovulation in some infertile patients. Therapy with gonadotropin initiates in the follicular phase of the menstrual cycle with FSH, followed by administration of hCG. Ovulation is expected between 36 and 48 hours after hCG injection. If fertilization occurs, progesterone is administered to ensure implantation and is maintained until approximately 10 weeks of gestation, when placental hormone production becomes sufficient. Assisted reproduction technologies are alternative options when therapy with gonadotropins fails (88). In a recent systematic literature review, the authors suggested that assisted fertility in women hypopituitarism has a good outcome both in terms of achieving pregnancy and infant outcome (94).

\section{GH DEFICIENCY (GHD) IN ADULTS}

A nationwide study carried out in Denmark has reported an annual incidence of adult GH deficiency (AGHD) of 17.6 per 1,000,000 people, with higher rates in men (95). Applying these numbers to the Brazilian population, we would expect approximately 3,700 new cases of AGHD yearly in our country. According to the age at onset, 
patients may present with childhood-onset (CO) AGHD or adulthood-onset AGHD (96-98). Isolated idiopathic GHD diagnosed in children based on biochemical GH tests must be reevaluated during transition into adult life. A Brazilian study reported that only $31 \%$ of the children with GHD persisted with GHD when retested, with an IGF-I cutoff value of $110 \mathrm{ng} / \mathrm{mL}$ presenting $94.5 \%$ sensitivity and $100 \%$ specificity for diagnosis of AGHD in the transition period (99). Noteworthy, short children treated with GH for non-GHD pediatric indications (e.g., Turner syndrome, idiopathic short stature, small for gestational age, etc.) and adults with functional GHD (obesity, metabolic syndrome, aging) without evidence of hypothalamic-pituitary disease must not be investigated for AGHD (100).

The clinical presentation of AGHD is characterized by multiple, nonspecific clinical findings involving changes in body composition, increased fracture risk, altered physical capacity, presence of cardiovascular risk factors, and poor QoL (101) (Table 4). These manifestations vary according to age, time of onset, and presence of other hormone deficiencies. For instance, low bone mass is more frequent in young adults with GHD, while cardiovascular risk factors are more common among older patients with GHD (102). In the United Kingdom, perceived impairment of QoL is required to initiate $\mathrm{GH}$ replacement in adults, while lack of improvement in QoL is used for discontinuation of GH therapy (103). QoL can be evaluated by general questionnaires or by the specific questionnaire Quality of Life Assessment of Growth Hormone Deficiency in Adults, which has been translated into Brazilian Portuguese and validated for the Brazilian population (104).

In an appropriate clinical context, the diagnosis of AGHD must be biochemically confirmed by serum IGF-I measurements alone or in association with $\mathrm{GH}$ stimulating tests. Basal serum GH levels have no diagnostic value due to the pulsatile nature of pituitary $\mathrm{GH}$ secretion. ITT is considered the gold-standard test, and severe GHD is diagnosed when the peak $\mathrm{GH}$ value is below $3 \mu \mathrm{g} / \mathrm{L}$ or $5 \mu \mathrm{g} / \mathrm{L}$ in the transition period (96$98,101,102)$. As mentioned before, ITT requires medical supervision and is contraindicated in elderly individuals and in patients with cardiac or neurologic diseases. An alternative to ITT is the GST, with a cutoff value of 3 $\mu \mathrm{g} / \mathrm{L}$ recommended to discriminate between normal response and severe $\mathrm{AGHD}$, or $1 \mu \mathrm{g} / \mathrm{L}$ in overweight/ obese subjects (51). Macimorelin acetate is an orally active ghrelin mimetic that binds to the $\mathrm{GH}$ secretagogues receptors and stimulates $\mathrm{GH}$ secretion. The macimorelin test for AGHD has a sensitivity and specificity of $92 \%$ and $96 \%$, respectively, with a diagnostic accuracy similar

Table 4. Clinical abnormalities in adult patients with hypopituitarism and growth hormone (GH) deficiency (AGHD) and effect of GH replacement therapy

\begin{tabular}{|c|c|c|}
\hline Clinical findings & Effects of AGHD & Effects of GH therapy \\
\hline Body composition & $\begin{array}{l}\text { Increased total/visceral fat } \\
\text { Reduced lean body mass } \\
\text { Reduced bone mass (especially during transition and young } \\
\text { adulthood) } \\
\text { Increased fracture risk }\end{array}$ & $\begin{array}{l}\text { Reduced total/visceral fat } \\
\text { Increased lean body mass } \\
\text { Increased bone mass } \\
\text { Reduced bone fractures }\end{array}$ \\
\hline Quality of life (QoL) & $\begin{array}{l}\text { Fatigue (low energy, reduced vitality) } \\
\text { Low mood } \\
\text { Low self-esteem } \\
\text { Reduced concentration } \\
\text { Reduced memory } \\
\text { Increase in sick days } \\
\text { Greater social isolation }\end{array}$ & $\begin{array}{l}\text { Improvement in women and patients with low QoL at } \\
\text { baseline }\end{array}$ \\
\hline Physical capacity & $\begin{array}{l}\text { Reduced muscle strength } \\
\text { Reduced maximum oxygen uptake }\left(\mathrm{VO}_{2}\right) \\
\text { Impaired cardiac function } \\
\text { Reduced anaerobic capacity }\end{array}$ & $\begin{array}{l}\text { Improvement of muscle strength (long term), maximum } \mathrm{VO}_{2} \text {, } \\
\text { cardiac function, and anaerobic capacity }\end{array}$ \\
\hline Cardiovascular risk factors & $\begin{array}{l}\text { Dyslipidemia } \\
\text { Hypertension } \\
\text { Abnormal fibrinolytic activity } \\
\text { Increased inflammatory markers } \\
\text { Increased intimal media thickening } \\
\text { Endothelial dysfunction }\end{array}$ & $\begin{array}{l}\text { Improvement in diastolic blood pressure, total cholesterol, } \\
\text { low-density lipoprotein cholesterol, and endothelial functions } \\
\text { Decreased inflammatory markers and intimal media } \\
\text { thickening }\end{array}$ \\
\hline
\end{tabular}


to that of ITT, without risk of hypoglycemia and less false-positive results. However, macimorelin acetate is an expensive medication and is not available in Brazil (101). Other GH tests commonly used in children to diagnose GHD are not recommended in adults due to very low accuracy (96-98). In patients with a high probability of AGHD, such as those with multiple pituitary hormone deficiencies associated with well-documented structural lesions in the hypothalamic-pituitary region, a low serum IGF-I level (below the lower limit of reference for age and sex) is enough to diagnose AGHD and precludes the need for a provocative GH test (96-98). However, factors interfering with IGF-I measurement should be considered, such as the use of oral estrogens, uncontrolled hypothyroidism, malnutrition, hepatic insufficiency, and uncontrolled diabetes, since these conditions may lead to false results. On the other hand, it is important to emphasize that normal IGF-I levels do not rule out the diagnosis of AGHD (96-98) (Table 5 and Figure 2).

Table 5. Biochemical tests available in Brazil for diagnosis of adult growth hormone (GH) deficiency (AGHD)

\begin{tabular}{|c|c|c|c|c|}
\hline Test & Protocol & Diagnosis criteria & Advantages & Considerations \\
\hline $\begin{array}{l}\text { Insulin tolerance } \\
\text { test (ITT) }\end{array}$ & $\begin{array}{l}0.1 \mathrm{U} / \mathrm{kg} \text { IV of regular insulin; } \\
\text { measure glucose and } \mathrm{GH} \text { at } \\
\text { baseline and } 30,60,90 \text {, and } 120 \\
\text { minutes after insulin }\end{array}$ & $\begin{array}{l}\mathrm{GH} \text { peak }<3 \mu \mathrm{g} / \mathrm{L}(<5 \mu \mathrm{g} / \mathrm{L} \text { in } \\
\text { the transition period })\end{array}$ & $\begin{array}{l}\text { Gold standard } \\
\text { May allow simultaneous } \\
\text { assessment of hypothalamic- } \\
\text { pituitary-adrenal axis }\end{array}$ & $\begin{array}{l}\text { Risk of serious adverse events } \\
\text { Requires supervision } \\
\text { Contraindicated in elderly } \\
\text { individuals and patients with } \\
\text { neurologic or cardiac disorders }\end{array}$ \\
\hline $\begin{array}{l}\text { Glucagon } \\
\text { stimulation } \\
\text { test (GST) }\end{array}$ & $\begin{array}{l}\text { Glucagon } 1 \mathrm{mg} \mathrm{IM} \mathrm{(1.5} \mathrm{mg} \mathrm{for} \\
\text { patients }>90 \mathrm{~kg} \text { ); measure } \\
\text { glucose and } \mathrm{GH} \text { at baseline and } \\
\text { every } 30 \text { minutes after glucagon } \\
\text { for } 3-4 \text { hours }\end{array}$ & $\begin{array}{l}\text { GH peak }<3 \mu \mathrm{g} / \mathrm{L}(<1.0 \mu \mathrm{g} / \mathrm{L} \text { in } \\
\text { overweight/obese individuals })\end{array}$ & $\begin{array}{l}\text { Glucagon is readily available } \\
\text { May allow simultaneous } \\
\text { assessment of hypothalamic- } \\
\text { pituitary-adrenal axis }\end{array}$ & $\begin{array}{l}\text { Adverse effects (nausea, } \\
\text { vomiting, headache) } \\
\text { Requires better standardization of } \\
\text { time points and cut-off values }\end{array}$ \\
\hline |GF-I & None & $\begin{array}{l}\text { Below the lower limit of normal } \\
\text { (adjusted for age) }\end{array}$ & Simple & $\begin{array}{l}\text { A normal value does not exclude } \\
\text { AGHD }\end{array}$ \\
\hline
\end{tabular}

IV: intravenous; IM: intramuscular.

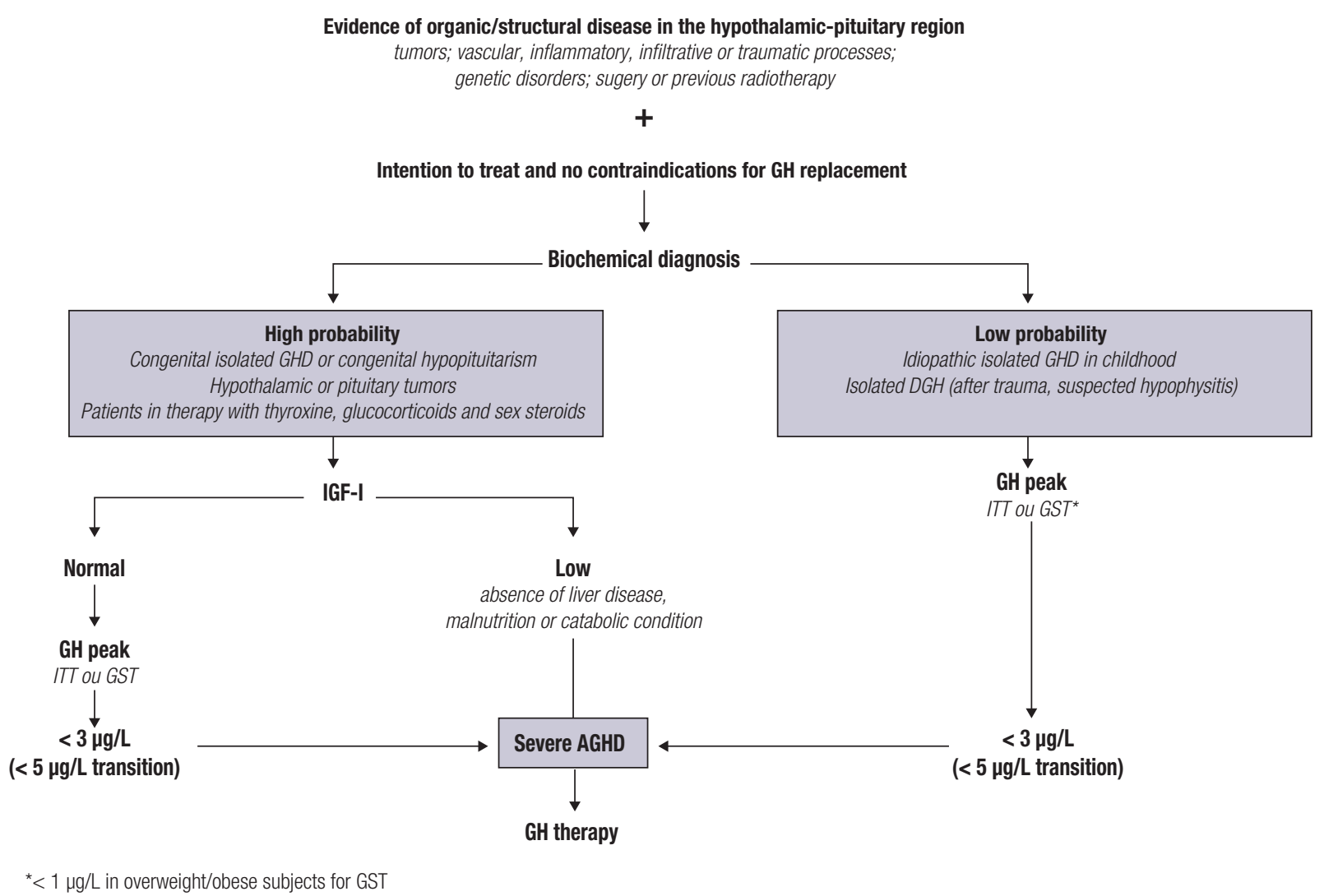

Figure 2. Algorithm for diagnosis of growth hormone (GH) deficiency in adult patients (AGHD) with hypopituitarism, considering only GH tests available in Brazil ITT: insulin tolerance test; GST: glucagon stimulation test. 
GH replacement therapy is indicated to all patients with a diagnosis of AGHD for whom treatment is intended (90). The main contraindications to $\mathrm{GH}$ therapyinclude active malignancy, uncontrolled diabetes, diabetic retinopathy, and intracranial hypertension (96-98). In Brazil, the Ministry of Health Ordinance number 28 of November 30, 2018, contemplates the "Clinical Protocol and Therapeutic Guidelines for Hypopituitarism", a document that regulates in the public health care system (SUS) the therapeutic use of $\mathrm{GH}$ in children and adults (105). In contrast with GH treatment in children, GH replacement doses in adults are not calculated based on body weight, because this approach results in a high frequency of adverse events, mainly related to fluid retention, including paresthesias, joint stiffness, peripheral edema, arthralgia, myalgia, and carpal tunnel syndrome. Thus, the starting dose of $\mathrm{GH}$ is $0.1 \mathrm{mg}$ for individuals 60 years or older, 0.2 $\mathrm{mg}$ for young men, $0.3 \mathrm{mg}$ for young women, and $0.4-0.7 \mathrm{mg}$ in the transition period, administered in daily subcutaneous injections at bedtime. The dose should be titrated every month until attaining IGF-I levels between the median and upper limit of normal for age (96-98). The maintenance dose generally varies between $0.4-0.6 \mathrm{mg} /$ day, with a large individual variability depending on sex, age, body mass index (BMI), and route of estrogen replacement in women, among other factors (98). SAI and $\mathrm{CH}$ can develop or worsen during GH therapy; therefore, cortisol and FT4 should be closely monitored with proper adjustments in glucocorticoid and LT4 replacement doses $(96-98,101,102)$. Anthropometry (BMI, waist circumference), blood pressure, and QoL should be assessed at each visit during follow-up for dose titration and every 6 months thereafter. Lipid profile, glycemia, and hemoglobin AlC can be evaluated every 6-12 months, while evaluation of body composition and BMD by dual-energy $x$-ray absorptiometry (DXA) and cardiovascular parameters is recommended yearly or every 2 years $(96-98,101,102)$.

$\mathrm{GH}$ replacement therapy improves or normalizes several abnormalities related to AGHD and may promote health benefits in patients with hypopituitarism (Table 4). In the transition period, continuation or reintroduction of $\mathrm{GH}$ therapy after attaining final height promotes full somatic development of bone and muscles and prevents the development of abnormal metabolic features observed in older patients with AGHD (96,102). Meta-analyses of placebo-controlled trials have shown that $\mathrm{GH}$ treatment in adults reduces total and visceral fat mass, increases lean body mass and bone mass, improves cardiovascular risk markers (diastolic blood pressure, total cholesterol, and LDLcholesterol), and increases anaerobic and exercise capacity $(106,107)$. However, individual responses to GH therapy concerning different therapeutic endpoints vary greatly, and not all patients show the same pattern of improvement (108). It is still unclear whether $\mathrm{GH}$ replacement improves QoL, but in cohorts of AGHD followed up for up to 10 years, sustained improvement in QoL scores toward normal values has been demonstrated, especially in women and patients with low QoL at baseline $(107,109)$.

$\mathrm{GH}$ replacement is generally safe and well tolerated in adult patients with hypopituitarism. However, special attention should be given to older, heavier, and female AGHD patients, as well as to those with a family history of type 2 diabetes, because they are more susceptible to adverse events, especially related to glucose homeostasis (110). In these individuals, close monitoring with fasting blood glucose and hemoglobin $\mathrm{AlC}$ is recommended during GH therapy. GH therapy should be initiated when pituitary tumor growth is under control. In this context, there is no evidence that long-term GH replacement in adults affects the progression of pituitary tumors. Additionally, there is no evidence of tumor recurrence or increased risk of neoplasia in AGHD; therefore, cancer surveillance in adult patients on GH therapy should follow the same standard practice as those in the general population (111).

The impact of untreated GHD on increasing mortality in patients with hypopituitarism is unclear. GH therapy does not change the prevalence of metabolic syndrome over time but, intriguingly, has been associated with reduction or even normalization of mortality in AGHD $(6,32,33,112,113)$. A possible reason for this apparent paradox is the positive GH effect on endothelial and cardiovascular parameters (75). Analysis of a Brazilian kindred with congenital isolated GHD due to a homozygous mutation in the $\mathrm{GH}$-releasing hormone $(\mathrm{GHRH})$ receptor gene showed no serious deleterious effect of congenital isolated GHD on risks of vascular events and survival (114). However, this finding should not be extended to patients with hypopituitarism and AGHD, who present a distinct phenotype (115). Unfortunately, randomized clinical trials evaluating the effect of $\mathrm{GH}$ 
therapy on mortality in AGHD are unavailable. Thus, the primary goal of GH replacement therapy should be oriented to improve the associated morbidities in the short and long term.

\section{HORMONAL INTERACTIONS DURING PITUITARY HORMONE REPLACEMENT}

Pituitary hypofunction usually requires replacement of several hormones, and it is essential to understand the main interactions between the different pituitary axes during hormone replacement to optimize the therapeutic outcomes. Prescription of thyroid hormones without previous replacement of glucocorticoids may precipitate an adrenal crisis in patients with ACTH deficiency. The mechanisms involved in cortisol reduction after LT4 treatment are not completely understood but may involve accelerated cortisol catabolism induced by an increase in renal $11 \beta$-hydroxysteroid dehydrogenase type 2 or increased urinary cortisol clearance due to augmented urinary flow caused by hypothyroidism treatment (68). Therefore, a careful investigation of SAI should be performed before initiating thyroid hormone therapy in patients with hypopituitarism, while the daily glucocorticoid dose may require adjustment in patients on glucocorticoid replacement who are started on LT4 treatment. Similarly, cortisol status must be monitored before and during $\mathrm{GH}$ replacement therapy, since $\mathrm{GH}$ reduces the activity of the $11 \beta$-hydroxysteroid dehydrogenase type $l$ in the liver and adipose tissue, an enzyme that converts inactive cortisone to active cortisol (96-98). Consequently, GH therapy can unmask subclinical SAI, requiring the initiation or adequation of glucocorticoid replacement (96-98). In addition, patients replaced with GH can develop a variable reduction in FT4 levels and a slight increase in free T3 levels (41). The underlying mechanisms likely involve enhancement of peripheral deiodination of T4 to T3 due to activation of deiodinase type $\mathrm{l}$ by $\mathrm{GH}$, reduction of residual TSH secretion due to an increase in somatostatinergic tonus determined by IGF-I action on hypothalamus, and/or reduction of residual TSH secretion due T3 feedback on the pituitary (116). Accordingly, FT4 levels should be evaluated 6 weeks after starting GH therapy, and LT4 initiation or dose adjustment may be necessary in patients with established $\mathrm{CH}$ to maintain FT4 levels in the adequate range (30).

Estrogen therapy may increase thyroxin binding protein (TBG) levels, reducing FT4 levels (117); consequently, the mean LT4 dose is usually higher in women on estrogen therapy than in those not taking estrogen (37). As previously mentioned, oral estrogen may antagonize GH action in the liver. This effect is induced by the expression of an intracellular protein named SOCS-2, which blocks GH signaling and reduces IGF-I generation (118). In addition, oral estrogens can interfere with IGFBPs levels during GH treatment. (119). Like oral estrogens, selective estrogen receptor modulators (SERMs) can also interfere with the hepatic IGF-I production (120). Thus, as previously mentioned, women with hypopituitarism and on GH replacement should receive estrogen via transdermal route. Taken together, all these interactions highlight the importance of constant clinical and laboratory monitoring of patients with hypopituitarism on replacement therapies to improve compliance, make appropriate adjustments, and optimize therapeutic outcomes (Figure 3).

\section{FINAL COMMENTS}

Management of hypopituitarism is one of the greatest challenges in clinical endocrinology, and several fundamental aspects for adequate control of this condition are presented in this document. Patients and family members must be educated to understand the particularities of hypopituitarism treatment and hormonal interactions. This is particularly important during clinical complications, surgeries, and any procedure that the patient may require. Physicians working in other specialties must also become knowledgeable in hormone replacement to be able to manage patients with hypopituitarism as needed.

Disclosure: no potential conflict of interest relevant to this article was reported. 


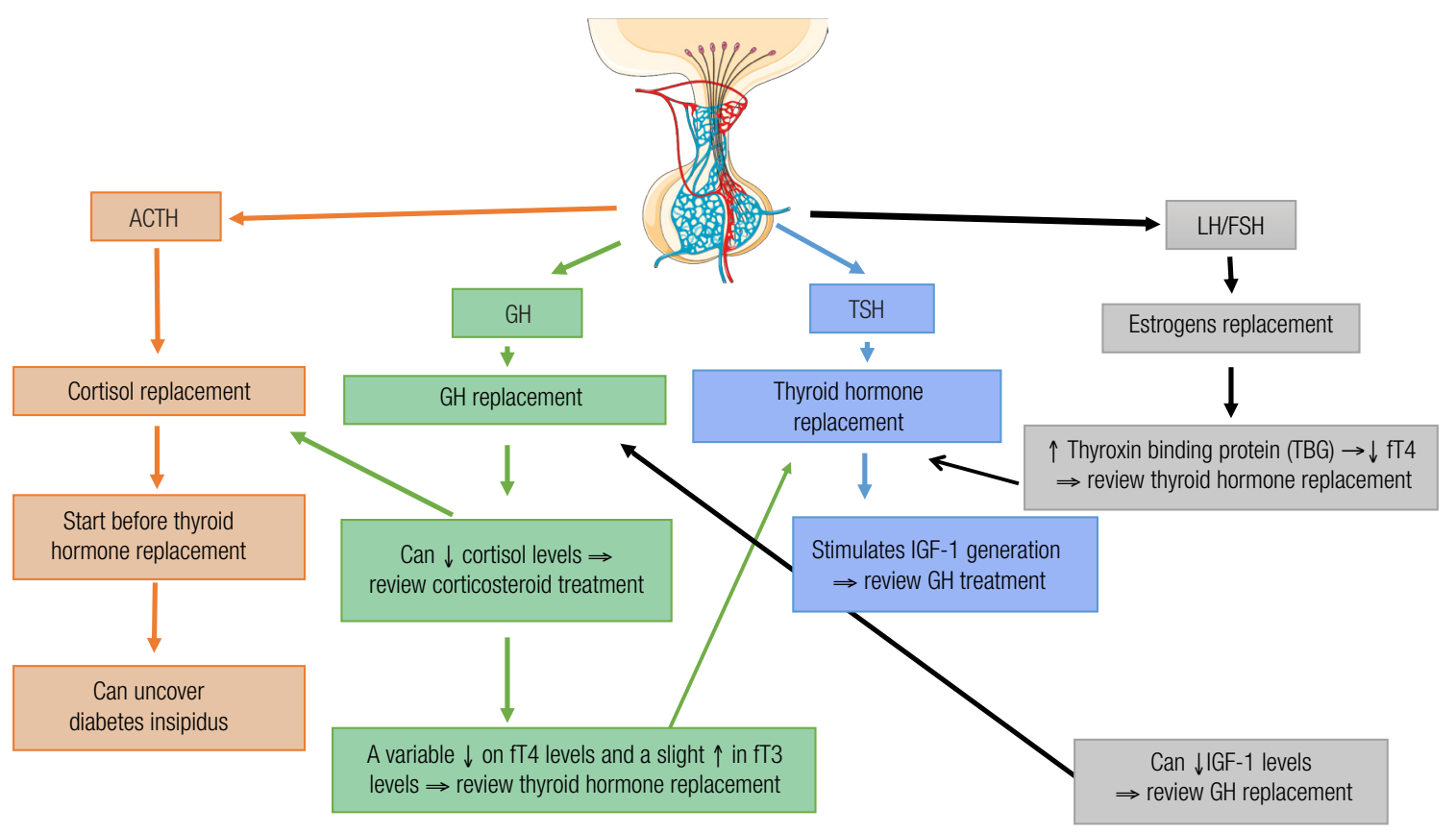

Figure 3. Pituitary hormone replacement and interactions.

fT4: free thyroxine; fT3: free triiodothyronine.

\section{REFERENCES}

1. Schneider HJ, Aimaretti G, Kreitschmann-Andermahr I, Stalla G-K, Ghigo E. Hypopituitarism. Lancet. 2007;369(9571):1461-70.

2. Regal M, Páramo C, Sierra SM, Garcia-Mayor RV. Prevalence and incidence of hypopituitarism in an adult Caucasian population in northwestern Spain. Clin Endocrinol (Oxf). 2001(6):735-40.

3. Stochholm K, Gravholt $\mathrm{CH}$, Laursen T, Jørgensen JO, Laurberg $\mathrm{P}$, Andersen M, et al. Incidence of GH deficiency - a nationwide study. Eur J Endocrinol. 2006;155(1):61-71.

4. RosénT, Bengtsson BA. Premature mortality due to cardiovascular disease in hypopituitarism. Lancet. 1990;336(8710):285-8.

5. Jasim S, Alahdab F, Ahmed AT, Tamhane S, Prokop LJ, Nippoldt TB, et al. Mortality in adults with hypopituitarism: a systematic review and meta-analysis. Endocrine. 2017;56(1):33-42.

6. Pappachan JM, Raskauskiene D, Kutty VR, Clayton RN. Excess mortality associated with hypopituitarism in adults: a metaanalysis of observational studies. J Clin Endocrinol Metab. 2015;100:1405-11.

7. Conklin SE, Knezevic CE. Advancements in the gold standard: Measuring steroid sex hormones by mass spectrometry. Clin Biochem. 2020;269:78-84.

8. Castillo AR, de Souza AL, Alegre SM, Atala YB, Zantut-Wittmann DE, Garmes HM. Insulin Sensitivity Is Not Decreased in Adult Patients With Hypopituitarism Without Growth Hormone Replacement. Front Endocrinol (Lausanne). 2019;10:534.

9. Sävendahl L, Battelino T, Brod M, Højby Rasmussen M, Horikawa $\mathrm{R}$, Juul RV, et al. Once-Weekly Somapacitan vs Daily GH in Children With GH Deficiency: Results From a Randomized Phase 2Trial. J Clin Endocrinol Metab. 2020;105(4):e1847-61.

10. Guarnotta V, Ciresi A, Pillitteri G, Giordano C. Improved insulin sensitivity and secretion in prediabetic patients with adrenal insufficiency on dual-release hydrocortisone treatment: a 36-month retrospective analysis. Clin Endocrinol (Oxf). 2018;88(5):665-72.
11. Xatzipsalti M, Voutetakis A, Stamoyannou L, Chrousos GP, Kanaka-Gantenbein C. Congenital Hypopituitarism: Various Genes, Various Phenotypes. Horm Metab Res. 2019;51(2):81-90.

12. Abe SY, Dos Santos KS, Barbosa BFB, Biondo CMP, Takito D, Hayashi SK, et al. Metabolic syndrome and its components in adult hypopituitary patients. Pituitary. 2020;23(4):409-16.

13. Karaca Z, Laway BA, Dokmetas HS, Atmaca H, Kelestimur F. Sheehan syndrome. Nat Rev Dis Primers. 2016;2:16092.

14. Schneider HJ, Kreitschmann-Andermahr I, Ghigo E, Stalla GK, Agha A. Hypothalamopituitary dysfunction following traumatic brain injury and aneurysmal subarachnoid hemorrhage: a systematic review. JAMA. 2007;298(12):1429-38.

15. Pereira JL, Albuquerque LA, Dellaretti M, Carvalho GT, Vieira $\mathrm{G} \mathrm{Jr}$, Brochado VM, et al. Pituitary deficiency after aneurysmal subarachnoid hemorrhage. Clinics (Sao Paulo). 2013;68(6):745-9.

16. Can A, Gross BA, SmithTR, Dammers R, Dirven CM, Woodmansee WW, et al. Pituitary Dysfunction After Aneurysmal Subarachnoid Hemorrhage: A Systematic Review and Meta-analysis. Neurosurgery. 2016;79(2):253-64.

17. Hacioglu A, Kelestimur F, Tanriverdi F. Long-term neuroendocrine consequences of traumatic brain injury and strategies for management. Expert Rev Endocrinol Metab. 2020;15(2):123-39.

18. Klose M, Feldt-Rasmussen U. Chronic endocrine consequences of traumatic brain injury - what is the evidence? Nat Rev Endocrinol. 2018;14(1):57-62.

19. Hohl A, Zanela FA, Ghisi G, Ronsoni MF, Diaz AP, Schwarzbold ML, et al. Luteinizing Hormone and Testosterone Levels during Acute Phase of Severe Traumatic Brain Injury: Prognostic Implications for Adult Male Patients. Front Endocrinol (Lausanne). 2018;9:29.

20. Hacioglu A, Kelestimur F, Tanriverdi F. Pituitary dysfunction due to sports-related traumatic brain injury. Pituitary. 2019;22(3):322-31.

21. Angelousi A, Chatzellis E, Kaltsas G. New Molecular, Biological, and Immunological Agents Inducing Hypophysitis. Neuroendocrinology. 2018;106(1):89-100.

22. Faje A. Hypophysitis: Evaluation and Management. Clin diabetes Endocrinol. 2016;2(1):15. 
23. Joshi MN, Whitelaw BC, Palomar MTP, Wu Y, Carroll PV. Immune checkpoint inhibitor-related hypophysitis and endocrine dysfunction: clinical review. Clin Endocrinol (Oxf). 2016;85(3):331-9.

24. Byun DJ, Wolchok JD, Rosenberg LM, Girotra M. Cancer immunotherapy - immune checkpoint blockade and associated endocrinopathies. Nat Rev Endocrinol. 2017;13(4):195-207.

25. Barroso-Sousa R, Barry WT, Garrido-Castro AC, Hodi FS, Min L, Krop IE, et al. Incidence of Endocrine Dysfunction Following the Use of Different Immune Checkpoint Inhibitor Regimens. JAMA Oncol. 2018;4(2):173.

26. Friedman CF, Proverbs-Singh TA, Postow MA. Treatment of the Immune-Related Adverse Effects of Immune Checkpoint Inhibitors. JAMA Oncol. 2016;2(10):1346.

27. Diamanti-Kandarakis E, Duntas L, Kanakis GA, Kandaraki E, Karavitaki N, Kassi E, et al. Diagnosis of endocrine disease: Druginduced endocrinopathies and diabetes: a combo-endocrinology overview. Eur J Endocrinol. 2019;181(2):R73-105.

28. Melmed S, Auchus RJ, Goldfine AB, Koenig RJ, Rosen CJ. Williams Textbook of Endocrinology 14th edition, 2020:184-235.

29. Higham CE, Johannsson G, Shalet SM. Hypopituitarism. Lancet. 2016;388(10058):2403-15.

30. Fleseriu M, Hashim IA, Karavitaki N, Melmed S, Murad MH, Salvatori R, et al. Hormonal Replacement in Hypopituitarism in Adults: An Endocrine Society Clinical Practice Guideline. J Clin Endocrinol Metab. 2016;101(11):3888-921.

31. Garmes HM, Castillo AR. Insulin signaling in the whole spectrum of GH deficiency. Arch Endocrinol Metab. 2019;63(6):582-91.

32. van der Klaauw AA, Biermasz NR, Feskens EJ, Bos MB, Smit JW, Roelfsema $F$, et al. The prevalence of the metabolic syndrome is increased in patients with GH deficiency, irrespective of longterm substitution with recombinant human GH. Eur J Endocrinol. 2007;156(4):455-62.

33. Attanasio AF, Mo D, Erfurth EM, Tan M, Ho KY, Kleinberg D, et al.; International Hypopituitary Control Complications Study Advisory Board. Prevalence of metabolic syndrome in adult hypopituitary growth hormone (GH)-deficient patients before and after GH replacement. J Clin Endocrinol Metab. 2010;95(1):74-81.

34. Verhelst J, Mattsson AF, Luger A, Thunander M, Góth MI, Koltowska-Häggström $M$, et al. Prevalence and characteristics of the metabolic syndrome in 2479 hypopituitary patients with adult-onset $\mathrm{GH}$ deficiency before GH replacement: a KIMS analysis. Eur J Endocrinol. 2011;165(6):881-9.

35. Beck-Peccoz P, Rodari G, Giavoli C, LaniaA. Central hypothyroidism - a neglected thyroid disorder. Nature Reviews Endocrinology. 2017;13(10):588-98.

36. Persani L, Brabant G, Dattani M, Bonomi M, Feldt-Rasmussen U, Fliers E, et al. 2018 EuropeanThyroid Association (ETA) Guidelines on the Diagnosis and Management of Central Hypothyroidism. EurThyroid J. 2018;7(5):225-37.

37. Alexopoulou O, Beguin C, De Nayer P, Maiter D. Clinical and hormonal characteristics of central hypothyroidism at diagnosis and during follow-up in adult patients. Eur $\mathrm{J}$ Endocrinol. 2004;150(1):1-8.

38. Doin FC, Rosa-Borges M, Martins MRA, Moisés VA, Abucham J. Diagnosis of subclinical central hypothyroidism in patients with hypothalamic-pituitary disease by Doppler echocardiography. Eur J Endocrinol. 2012;166(4):631-40.

39. Ferretti E, Persani L, Jaffrain-Rea ML, Giambona S, Tamburrano G, Beck-Peccoz P. Evaluation of the adequacy of levothyroxine replacement therapy in patients with central hypothyroidism. J Clin Endocrinol Metab. 1999;84(3):924-9.

40. Slawik M, Klawitter B, Meiser E, Schories M, Zwermann O, Borm $\mathrm{K}$, et al. Thyroid hormone replacement for central hypothyroidism: a randomized controlled trial comparing two doses of thyroxine
(T4) with a combination of T4 and triiodothyronine. J Clin Endocrinol Metab. 2007;92(11):4115-22.

41. Martins MRA, Doin FC, Komatsu WR, Barros-Neto TL, Moises VA, Abucham J. Growth hormone replacement improves thyroxine biological effects: Implications for management of central hypothyroidism. J Clin Endocrinol Metab. 2007;92(11):4144-53.

42. Klose M, Marina D, Hartoft-Nielsen ML, Klefter O, Gavan V, Hilsted L, et al. Central hypothyroidism and its replacement have a significant influence on cardiovascular risk factors in adult hypopituitary patients. J Clin Endocrinol Metab. 2013;98(9):3802-10.

43. Mazziotti G, Mormando M, Cristiano A, Bianchi A, Porcelli T, Giampietro A, et al. Association between I-thyroxine treatment, GH deficiency, and radiological vertebral fractures in patients with adult-onset hypopituitarism. Eur J Endocrinol. 2014;170(6):893-9.

44. Alexander EK, Pearce EN, Brent GA, Brown RS, Chen H, Dosiou C, et al. 2017 Guidelines of the American Thyroid Association for the Diagnosis and Management of Thyroid Disease During Pregnancy and the Postpartum. Thyroid. 2017;27(3):315-89.

45. Guaraldi F, Karamouzis I, Berardelli R, D’Angelo V, Rampino A, Zichi $C$, et al. Secondary Adrenal Insufficiency: Where Is It Hidden and What Does It Look Like? Front Horm Res. 2016;46:159-70.

46. Bancos I, Hahner S, Tomlinson J, Arlt W. Diagnosis and management of adrenal insufficiency. Lancet Diabetes Endocrinol. 2015;3(3):216-26.

47. Araujo PB, Coelho MC, Arruda M, Gadelha MR, Neto LV. Ipilimumab-induced hypophysitis: review of the literature. J Endocrinol Invest. 2015;38(11):1159-66.

48. Burman $P$, Mattsson AF, Johannsson G, Höybye $C$, Holmer $H$, Dahlqvist $P$, et al. Deaths among adult patients with hypopituitarism: hypocortisolism during acute stress, and de novo malignant brain tumors contribute to an increased mortality. J Clin Endocrinol Metab. 2013;98(4):1466-75.

49. Allolio B. Extensive expertise in endocrinology. Adrenal crisis. Eur J Endocrinol. 2015;172(3):R115-24.

50. Pastores SM, Annane D, Rochwerg B; Corticosteroid Guideline Task Force of SCCM and ESICM. Guidelines for the Diagnosis and Management of Critical IIIness-Related Corticosteroid Insufficiency (CIRCI) in Critically III Patients (Part II): Society of Critical Care Medicine (SCCM) and European Society of Intensive Care Medicine (ESICM) 2017. Crit Care Med. 2018;46(1):146-8.

51. Boguszewski CL. Glucagon stimulation test: has its time come? Endocrine. 2017;57:361-3.

52. Clark PM, Neyton I, Raggatt PR, Sheppard MC, Stewart PM. Defining the normal cortisol response to the short Synacthen test: implications for the investigation of hypothalamic-pituitary disorders. Clin Endocrinol (Oxf). 1998;49(3):287-92.

53. Ospina NS, Al Nofal A, Bancos I, Javed A, Benkhadra K, Kapoor E, et al. ACTH Stimulation Tests for the Diagnosis of Adrenal Insufficiency: Systematic Review and Meta-Analysis. J Clin Endocrinol Metab. 2016;101(2):427-34.

54. Krasowski MD, Drees D, Morris CS, Maakestad J, Blau JL, Ekins S. Cross-reactivity of steroid hormone immunoassays: clinical significance and two-dimensional molecular similarity prediction. BMC Clin Pathol. 2014;14:33.

55. Monaghan PJ, Keevil BG, Trainer PJ.The use of mass spectrometry to improve the diagnosis and the management of the HPA axis. Rev Endocr Metab Disord. 2013;14(2):143-57.

56. Boolani A, Channaveerappa D, Dupree EJ, Jayathirtha M, Aslebagh R, Grobe S, et al. Trends in Analysis of Cortisol and Its Derivatives. Adv Exp Med Biol. 2019;1140:649-64.

57. Bornstein SR, Allolio B, Arlt W, Barthel A, Don-Wauchope A, Hammer GD, et al. Diagnosis and Treatment of Primary Adrenal Insufficiency: An Endocrine Society Clinical Practice Guideline. J Clin Endocrinol Metab. 2016;101(2):364-89. 
58. Forss M, Batcheller G, Skrtic S, Johannsson G. Current practice of glucocorticoid replacement therapy and patient-perceived health outcomes in adrenal insufficiency - a worldwide patient survey. BMC Endocr Disord. 2012;12:8.

59. Al Nofal A, Bancos I, Benkhadra K, Ospina NM, Javed A, Kapoor E, et al. Glucocorticoid Replacement Regimens in Chronic Adrenal Insufficiency: A Systematic Review and Meta-Analysis. Endocr Pract. 2017;23(1):17-31.

60. Stewart PM. Modified-Release Hydrocortisone: Is It Time to Change Clinical Practice? J Endocr Soc. 2019;3(6):1150-3.

61. Murray RD, Ekman B, Uddin S, Marelli C, Quinkler M, Zelissen PM, the EU-AIR Investigators. Management of glucocorticoid replacement in adrenal insufficiency shows notable heterogeneity - data from the EU-AIR. Clin Endocrinol (Oxf). 2017;86(3):340-6.

62. Johannsson G, Falorni A, Skrtic S, Lennernäs $H$, Quinkler $M$, Monson JP, et al. Adrenal insufficiency: review of clinical outcomes with current glucocorticoid replacement therapy. Clin Endocrinol (Oxf). 2015;82(1):2-11.

63. Young J, Xu C, Papadakis GE, Acierno JS, Maione L, Hietamäki $\mathrm{J}$, et al. Clinical Management of Congenital Hypogonadotropic Hypogonadism. Endocr Rev. 2019;40(2):669-710.

64. Pivonello R, Menafra D, Riccio E, Garifalos F, Mazzella M, de Angelis $\mathrm{C}$, et al. Metabolic disorders and male hypogonadotropic hypogonadism. Front Endocrinol (Lausanne). 2019;10:345.

65. Gagliano-Jucá T, Basaria S. Testosterone replacement therapy and cardiovascular risk. Nat Rev Cardiol. 2019;16(9):555-74.

66. Tomlinson JW, Holden N, Hills RK, Wheatley K, Clayton RN, Bates AS, et al. Association between premature mortality and hypopituitarism. West Midlands Prospective Hypopituitary Study Group. Lancet. 2001;357(9254):425-31.

67. Bhasin S, Brito JP, Cunningham GR, Hayes FJ, Hodis HN, Matsumoto AM, et al. Testosterone Therapy in Men With Hypogonadism: An Endocrine Society Clinical Practice Guideline. J Clin Endocrinol Metab. 2018;103(5):1715-44.

68. Alexandraki KI, Grossman A. Management of hypopituitarism. J Clin Med. 2019;8(12). pii: E2153.

69. Thirumalai A, Berkseth KE, Amory JK. Treatment of hypogonadism: current and future therapies. F1000Res. 2017;6:68.

70. Tsametis $C P$, Isidori $A M$. Testosterone replacement therapy: For whom, when and how? Metabolism. 2018;86:69-78.

71. Yassin AA, Haffejee M. Testosterone depot injection in male hypogonadism: a critical appraisal. Clin Interv Aging. 2007;2(4):577-90.

72. Ronald S Swerdloff, Christina Wang, William B White, Jed Kaminetsky, Marc C Gittelman, James A Longstreth, Robert E Dudley, Theodore M Danoff. A New Oral Testosterone Undecanoate Formulation Restores Testosterone to Normal Concentrations in Hypogonadal Men. J Clin Endocrinol Metab. 2020;105(8):2515-31.

73. Gronski MA, Grober ED, Gottesman IS, Ormsby RW, Bryson N. Efficacy of nasal testosterone gel (Natesto ${ }^{\circledR}$ ) stratified by baseline endogenous testosterone levels. J Endocr Soc. 2019;3(9):1652-62.

74. Kaminetsky JC, McCullough A, Hwang K, Jaffe JS, Wang C, Swerdloff RS. A 52-Week Study of Dose Adjusted Subcutaneous Testosterone Enanthate in Oil Self-Administered via Disposable Auto-Injector. J Urol. 2019;201(3):587-94.

75. Miljić D, Popovic V. Metabolic Syndrome in Hypopituitarism. Front Horm Res. 2018;49:1-19.

76. Zhu D, Chung HF, Dobson AJ, Pandeya N, Brunner EJ, Kuh D, et al. Type of menopause, age of menopause and variations in the risk of incident cardiovascular disease: pooled analysis of individual data from 10 international studies. Hum Reprod. 2020 Aug 1;35(8):1933-43.
77. Lindholm J, Nielsen EH, Bjerre P, Christiansen JS, Hagen C, Juul $\mathrm{S}$, et al. Hypopituitarism and mortality in pituitary adenoma. Clin Endocrinol (Oxf). 2006;65(1):51-8.

78. Olivius C, Landin-Wilhelmsen K, Olsson DS, Johannsson G, Tivesten $\AA$. Prevalence and treatment of central hypogonadism and hypoandrogenism in women with hypopituitarism. Pituitary. 2018;21(5):445-53.

79. Birzniece V, Ho KKY. Sex steroids and the GH axis: Implications for the management of hypopituitarism. Best Pract Res Clin Endocrinol Metab. 2017;31(1):59-69.

80. Pardini D. Hormone replacement therapy in menopause. Arq Bras Endocrinol Metabol. 2014;58(2):172-81.

81. Giraldo H, Benetti-Pinto C, Ferreira V, Garmes H, Yela D, Giraldo P. Standard hormone therapy is inadequate for bone density in premature ovarian insufficiency. Gynecol Endocrinol. 2017;33(4):283-86.

82. Nutis M, García KM, Nuwayhid B, Mulla Z, ElMasri W. Use of ultrasonographic cut point for diagnosing endometrial pathology in postmenopausal women with multiple risk factors for endometrial cancer. J Reprod Med. 2008;53(10):755-9.

83. Oliver-Williams C, Glisic M, Shahzad S, Brown E, Pellegrino Baena $\mathrm{C}$, Chadni $\mathrm{M}$, et al. The route of administration, timing, duration and dose of postmenopausal hormone therapy and cardiovascular outcomes in women: a systematic review. Hum Reprod Update. 2019;25(2):257-71.

84. Johannsson $G$, Burman $P$, Wirén $L$, Engström BE, Nilsson AG, Ottosson $M$, et al. Low dose dehydroepiandrosterone affects behavior in hypopituitary androgen-deficient women: a placebocontrolled trial. J Clin Endocrinol Metab. 2002;87(5):2046-52.

85. Wierman ME, Arlt W, Basson R, Davis SR, Miller KK, Murad MH, et al. Androgen therapy in women: a reappraisal: an Endocrine Society clinical practice guideline. J Clin Endocrinol Metab. 2014;99(10):3489-510.

86. Weiss RV, Hohl A, Athayde A, Pardini D, Gomes L, Oliveira M, et al. Testosterone therapy for women with low sexual desire: a position statement from the Brazilian Society of Endocrinology and Metabolism. Arch Endocrinol Metab. 2019;63(3):190-8.

87. Vegunta S, Kling JM, Kapoor E. Androgen Therapy in Women. J Womens Health (Larchmt). 2020;29(1):57-64.

88. Marques JVO, Boguszewski CL. Fertility issues in aggressive pituitary tumors. Rev Endocr Metab Disord. 2020;21(2):225-33.

89. Petersenn S, Christ-Crain M, Droste M, Finke R, Flitsch J, Kreitschmann-Andermahr I, et al. Pituitary Disease in Pregnancy: Special Aspects of Diagnosis and Treatment? Geburtshilfe Frauenheilkd. 2019;79(4):365-74.

90. Ribeiro RS, Abucham J. Recovery of persistent hypogonadism by clomiphene in males with prolactinomas under dopamine agonist treatment. Eur J Endocrinol. 2009;161(1):163-9.

91. Ribeiro RS, Abucham J. Clomiphene fails to revert hypogonadism in most male patients with conventionally treated nonfunctioning pituitary adenomas. Arq Bras Endocrinol Metabol. 2011;55(4):266-71.

92. Duarte FH, Jallad RS, Bronstein MD. Clomiphene citrate for treatment of acromegaly not controlled by conventional therapies. J Clin Endocrinol Metab. 2015;100(5):1863-9.

93. Thau RB, Goldstein M, YamamotoY, Burrow GN, Phillips D, Bardin $\mathrm{CW}$. Failure of gonadotropin therapy secondary to chorionic gonadotropin-induced antibodies. J Clin Endocrinol Metab. 1988;66(4):862-7.

94. Vila G, Fleseriu M. Fertility and Pregnancy in Women With Hypopituitarism: A Systematic Literature Review. J Clin Endocrinol Metab. 2020;105(3):e53-e65.

95. Stochholm K, Gravholt CH, Laursen T, Jørgensen JO, Laurberg $\mathrm{P}$, Andersen M, et al. Incidence of GH deficiency - a nationwide study. Eur J Endocrinol. 2006;155(1):61-71. 
96. Ho KK, 2007 GH Deficiency Consensus Workshop Participants. Consensus guidelines for the diagnosis and treatment of adults with GH deficiency II: statement of the GH Research Society in association with the European Society for Pediatric Endocrinology, Lawson Wilkins Society, European Society of Endocrinology, Japan Endocrine Society, and Endocrine Society of Australia. Eur J Endocrinol. 2007;157(6):695-700.

97. Molitch ME, Clemmons DR, Malozowski S, Merriam GR, Vance ML. Evaluation and treatment of adult growth hormone deficiency: an endocrine society clinical practice guideline. J Clin Endocrinol Metab. 2011;96:1587-609.

98. Boguszewski CL. Update on GH therapy in adults. F1000Research 2017;6:2017.

99. Boguszewski CL, Lacerda CS, Lacerda Filho L, Carvalho JA, Boguszewski MCS. Reappraisal of serum insulin-like growth factor-I (IGF-1) measurement in the detection of isolated and combined growth hormone deficiency (GHD) during the transition period. Arq Bras Endocrinol Metabol. 2013;57:709-16.

100. Clemmons DR, Molitch M, Hoffman AR, Klibanski A, Strasburger CJ, Kleinberg DL, et al. Growth hormone should be used only for approved indications. J Clin Endocrinol Metab. 2014;99(2):409-11.

101. Melmed S. Pathogenesis and diagnosis of growth hormone deficiency in adults. N Engl J Med. 2019;380:2551-62.

102. Clayton P, Gleeson H, Monson J, Popovic V, Shalet SM, Christiansen JS. Growth hormone replacement throughout life: insights into age-related responses to treatment. Growth Horm IGF Res. 2007;17:369-82.

103. National Institute for Health and Clinical Excellence. Human growth hormone (somatropin) in adults with growth hormone deficiency. London: National Institute for Health and Clinical Excellence; 2003.

104. Ribeiro-Oliveira A, Mol SS, Twiss J, Alencar GA, Miranda PAC, Naves LA, et al. The Brazilian version of the Quality of Life Assessment of Growth Hormone Deficiency in Adults (QoLAGHDA): Four-stage translation and validation. Arq Bras Endocrinol Metabol. 2010;54(9):833-41.

105. Diário Oficial da União. Portaria Conjunta $\mathrm{N}^{\circ} 28$, de 30 de Novembro de 2018. Available from: http://www.in.gov.br/ materia/-/asset_publisher/Kujrw0TZC2Mb/content/id/55216762/ do1-2018-12-14-portaria-conjunta-n-28-de-30-de-novembrode-2018-55216742. Accessed in: July 31, 2020.

106. Chikani V, Cuneo RC, Hickman I, Ho KK. Growth hormone (GH) enhances anaerobic capacity: impact on physical function and quality of life in adults with GH deficiency. Clin Endocrinol (Oxf). 2016;85:660-8.

107. Jørgensen JOL, Juul A. Growth hormone replacement therapy in adults: 30 years of personal clinical experience. Eur J Endocrinol. 2018;179:R47-56.

108. Boguszewski CL. Individual sensitivity to growth hormone replacement in adults. Rev Endocr Metab Disord. 2020 Oct 7. doi: 10.1007/s11154-020-09605-1.
109. Mo D, Blum WF, Rosilio M, Webb SM, Qi R, Strasburger CJ. Ten-year change in quality of life in adults on growth hormone replacement for growth hormone deficiency: an analysis of the hypopituitary control and complications study. J Clin Endocrinol Metab. 2014;99:4581-8.

110. Allen DB, Backeljauw P, Bidlingmaier M, Biller BM, Boguszewski $M$, Burman $\mathrm{P}$, et al. GH safety workshop position paper: a critical appraisal of recombinant human $\mathrm{GH}$ therapy in children and adults. Eur J Endocrinol. 2016;174:1-9.

111. Boguszewski $\mathrm{CL}$, Boguszewski MCDS. Growth Hormone's Links to Cancer. Endocr Rev. 2019;40(2):558-74.

112. Claessen KM, Appelman-Dijkstra NM, Adoptie DM, Roelfsema F, Smit JW, Biermasz NR, et al. Metabolic profile in growth hormone-deficient (GHD) adults after long-term recombinant human growth hormone (rhGH) therapy. J Clin Endocrinol Metab. 2013;98(1):352-61.

113. Weber MM, Biller BM, Pedersen BT, Pournara E, Christiansen JS, Höybye C. The effect of growth hormone (GH) replacement on blood glucose homeostasis in adult nondiabetic patients with GH deficiency: real-life data from the NordiNet ${ }^{\circledR}$ International Outcome Study. Clin Endocrinol (Oxf). 2017;86(2):192-8.

114. Aguiar-Oliveira MH, Souza AHO, Oliveira CRP, Campos VC, Oliveira-Neto LA, Salvatori R. The multiple facets of GHRH/GH/ IGF-I axis: lessons from lifetime, untreated, isolated GH deficiency due to a GHRH receptor gene mutation. Eur J Endocrinol. 2017; 177:R85-97.

115. Biscotto IP, Costa Hong VA, Batista RL, Mendonca BB, Arnhold IJP, Bortolotto LA, et al. Vasculometabolic effects in patients with congenital growth hormone deficiency with and without $\mathrm{GH}$ replacement therapy during adulthood. Pituitary. 2020 Oct 24. doi: 10.1007/s11102-020-01099-z.

116. Keskin M, Bayramoglu E, Aycan Z. Effects of 1-year growth hormone replacement therapy on thyroid volume and function of the children and adolescents with idiopathic growth hormone deficiency. J Pediatr Endocrinol Metab. 2017;30(11):1187-90.

117. Arafah BM. Increased need for thyroxine in women with hypothyroidism during estrogen therapy. N Engl J Med. 2001;344(23):1743-9.

118. Leung KC, Johannsson G, Leong GM, Ho KK. Estrogen regulation of growth hormone action. Endocr Rev. 2004;25(5):693-721.

119. Isotton AL, Wender MC, Casagrande A, Rollin G, Czepielewski MA. Effects of oral and transdermal estrogen on IGF-1, IGFBP-3, IGFBP1, serum lipids, and glucose in patients with hypopituitarism during $\mathrm{GH}$ treatment: a randomized study. Eur J Endocrinol 2012;166(2):207-13.

120. Duarte FH, Jallad RS, Bronstein MD. Estrogens and selective estrogen receptor modulators in acromegaly. Endocrine. 2016;54(2):306-14. 